\title{
Tempering potential-based evaluation of the courtyard microclimate as a combined function of aspect ratio and outdoor temperature
}

\author{
Carlos Rivera-Gómez*, Eduardo Diz-Mellado, Carmen Galán-Marín, Victoria López-Cabeza \\ Departamento de Construcciones Arquitectónicas 1, Escuela Técnica Superior de, Arquitectura, Universidad de Sevilla, Avda. Reina Mercedes, 2, 41012 Seville, Spain
}

\section{A R T I C L E I N F O}

\section{Keywords:}

Climate change

Courtyards monitoring

Aspect ratio

Diurnal thermal range

Maximum outdoor temperature

Climate zoning

\begin{abstract}
A B S T R A C T
Courtyards are traditional construction models in Mediterranean cities. In this research, tempering performance of courtyards during a two-year field monitoring campaign in southern Spain was investigated. The main objective was to identify the thermal functions of inner courtyards, analyzing the aspect ratio (AR) and the influence of outdoor temperature to offer a perspective that contributes to the development of passive cooling strategies for urban housing. This investigation also reviewed these climate modifiers, in light of the average lifespan of a building, to establish thermal tempering guidelines to mitigate the effects of climate change. The results show that, although the AR is a determining factor in maximizing the courtyard tempering potential, other parameters such as diurnal temperature range (DTR) or maximum outdoor temperature (MOT) can significantly modify the influence of the AR. The study demonstrates these interactions verifying, for the climates studied, that courtyards with $\mathrm{AR}>3$ are appropriate solutions, especially in the warmest zones, enhancing microclimate management in summer. Results evince that courtyard maximum thermal performance is related to MOT increase. This factor is crucial to establish a tempering initial potential for a given courtyard. Apart from this, a complete daily cycle analysis through DTR confirms and clarifies this thermal buffer effect.
\end{abstract}

\section{Introduction}

Climate change is one of the most important global concerns at present, therefore, all disciplines, including architecture, must consider the range of climatic factors that can help palliate the effects of climate change. Courtyards as thermal tempering tools are becoming more and more behavior in a world with increasingly high temperatures (Stocker et al., 2013). International organizations such as the UN admonish countries to take drastic measures against climate change (United Nation, 2019). The Paris Agreement on climate change aimed to limit global warming to $2{ }^{\circ} \mathrm{C}$ (United Nations, 2015), while the last climate change summit, held in Katowice (Poland) on 3 December 2018, set guidelines for the correct implementation of the Paris Agreement for 2020.

This strategic framework conceived to mitigate climate change adds to the growing importance of the courtyard effect, especially in warm regions such as southern Europe. It is expected that this region will be severely affected by global warming, especially the Mediterranean basin. In 2015, the Mediterranean Experts on Climate and Environmental Change (MedECC) network was created as a decisionmaking body to tackle the impact of climate change in this zone; the network is open to all experts and scientists working to reduce the effects of climate change in this geographical area (MECEC, 2019). Studies conducted by the Intergovernmental Panel on Climate Change (IPCC) reveal disturbing data for the south of the Iberian Peninsula. The reports collected by the Regional Ministry of the Environment and Regional Planning of the Junta de Andalucía (Junte, 2019) include forecasts of annual average temperature increases of up to $5^{\circ} \mathrm{C}$ in some interior areas of the region, and up to $3^{\circ} \mathrm{C}$ in Mediterranean coastal areas where global warming will impact less.

Energy efficiency and whole-building thermal performance are based on design criteria established after considering statistical weather and climate information records that do not contemplate local long- and medium-term forecasts. Therefore, from the architectonic point of view, a thorough analysis of the repercussions of the IPCC climate scenarios is crucial for a better understanding of tomorrow's building performance (Rubio-Bellido, Pulido-Arcas, \& Ureta-Gragera, 2015). As interest grows in thermal comfort in regions that face a substantial temperature increase in the coming decades (a common theme in this research field), inner courtyards have been widely discussed as an interactive space between urban and architectural scales (Bitan, 1988). The courtyard has been a traditional architectural resource common to buildings in warm-climate Mediterranean cities. Thermal regulation provided by passive strategies such as courtyard design can lead to considerable

\footnotetext{
* Corresponding author.

E-mail address: crivera@us.es (C. Rivera-Gómez).
} 


\begin{tabular}{|llll|}
\hline \multicolumn{2}{|l|}{ Nomenclature } & CTP & climate thermal pattern \\
CS & case study & TG & thermal gap \\
AR & aspect ratio & $T_{\min }$ & minimum temperature \\
DTR & diurnal thermal range & $T_{\max }$ & maximum temperature \\
MOT & maximum outdoor temperature & CT & courtyard temperature \\
& & $T^{a}$ & temperature \\
\hline
\end{tabular}

energy savings (Abdulkareem, 2016). As a consequence, people's comfort can be achieved with lower energy consumption, while having a positive impact on the evolution of climate change. Courtyard thermal damping is a factor to consider, as it reduces the building's temperature without resorting to mechanical procedures that increase the heat island effect in cities.

Previous studies of low-rise housing in The Netherlands show how courtyards improve the energy efficiency of the building, with gains accrued in specific seasons of the year (Taleghani, Tenpierik, \& van den Dobbelsteen, 2014a). Even in countries that are not traditionally warmclimate, like The Netherlands, the courtyard has been analyzed in strategies for orientation, geometry and pavement materials (Taleghani, Tenpierik, \& van den Dobbelsteen, 2014b). Some of these studies were carried out by applying simulations and measurements, and have yielded interesting data. Correct climate analysis is crucial in the conception of thermal comfort conditions. Just as the ventilated roof has become the most significant constructive element in warm humid climates (Guimarães Merçon, 2008), the courtyard, under the right conditions, could be a tool for improving residents' comfort inside the buildings.

With interest in courtyards increasing in recent years, many studies based on a range of approaches have examined the microclimatic behavior of the courtyard. Some literature reviews have focused on this specific topic (Al-Masri \& Abu-Hijleh, 2012; Zamani, Heidari, \& Hanachi, 2018; Taleghani, 2018). Most of these studies emphasize the importance of variables such as courtyard geometry, in some cases considered as aspect ratio (AR) or as sky view factor (SVF) (Abdulkareem, 2016; Aldawoud, 2008; Al-Masri \& Abu-Hijleh, 2012;

Table 1

State-of-the-art review of passive cooling strategies on courtyard buildings.

\begin{tabular}{|c|c|c|c|c|c|c|c|}
\hline \multirow[t]{2}{*}{ Authors/year } & \multirow[t]{2}{*}{ Case studies } & \multicolumn{6}{|c|}{ Passive cooling approach } \\
\hline & & Geometry AR/SVF & Orientation & Climate location & Shading & Vegetation & Albedo \\
\hline Zamani et al. (2018) & Literature review & $\times$ & $\times$ & $\times$ & $\times$ & $\times$ & $\times$ \\
\hline Huang et al. (2016) & Traditional dwelling buildings in Lhasa (China) & $\times$ & $\times$ & $\times$ & $\times$ & - & $\times$ \\
\hline Ghaffarianhoseini et al. (2015) & Different building types (Malaysia) & $\times$ & $\times$ & $\times$ & - & $\times$ & $\times$ \\
\hline Soflaei et al. (2017) & Traditional houses (Iran) & $\times$ & $\times$ & $\times$ & $\times$ & - & - \\
\hline Rojas et al. (2012) & Mediterranean courtyards (Spain) & $\times$ & $\times$ & $\times$ & - & - & - \\
\hline Rodríguez-Algeciras et al. (2018) & Houses in historical center (Camagüey, Cuba) & $\times$ & $\times$ & $\times$ & - & - & - \\
\hline Nasrollahi et al. (2017) & 45 traditional houses in Shiraz (Iran) & $\times$ & $\times$ & $\times$ & - & - & - \\
\hline Muhaisen (2006) & Simulated coutyards & $\times$ & $\times$ & $\times$ & - & - & - \\
\hline Guedouh and Zemmouri (2017) & Different Buildings in Biskra (Algeria) & $\times$ & $\times$ & $\times$ & - & - & - \\
\hline Taleghani et al. (2015) & Different courtyards (Netherlands) & $\times$ & $\times$ & $\times$ & - & - & - \\
\hline Xu et al. (2018) & Museum in Yixin (China) & $\times$ & $\times$ & $\times$ & - & - & - \\
\hline Cindel et al. (2018) & Open places and models & $\times$ & $\times$ & - & $\times$ & $\times$ & $\times$ \\
\hline Toe and Kubota, (2015)) & Traditional Malay Houses (Malaysia) & $\times$ & $\times$ & - & - & $\times$ & $\times$ \\
\hline Cantón et al. (2014) & School Building in Mendoza (Argentina) & $\times$ & $\times$ & - & - & $\times$ & - \\
\hline Taleghani et al. (2014b) & Block dwellings (Netherlands) & $\times$ & $\times$ & - & - & - & $\times$ \\
\hline Manioğlu and Oral (2015)) & Simulated coutyard & $\times$ & $\times$ & - & - & - & $\times$ \\
\hline Almhafdy et al. (2015a) & General Hospital (Malaysia) & $\times$ & $\times$ & - & - & - & - \\
\hline Muhaisen and Gadi (2006) & Simulated coutyards & $\times$ & $\times$ & - & - & - & - \\
\hline Soflaei et al. (2016) & Traditional courtyard houses (Iran) & $\times$ & $\times$ & - & - & - & - \\
\hline Qaid and Ossen (2015) & Single courtyard. Putrajaya Boulevard (Malaysia) & $\times$ & $\times$ & - & - & - & - \\
\hline Martinelli and Matzarakis (2017)) & Different courtyards (Italy) & $\times$ & - & $\times$ & - & - & $\times$ \\
\hline Yaşa and Ok (2014) & Courtyard with different shapes (model) & $\times$ & - & $\times$ & - & - & - \\
\hline Aldawoud (2008) & Simulated coutyard & $\times$ & - & $\times$ & - & - & - \\
\hline Rojas-Fernández et al. (2017) & Residential and tertiary buildings in Andalucia (Spain) & $\times$ & - & $\times$ & - & - & - \\
\hline Jihad and Tahiri (2016) & Simulated courtyard (Morocco) & $\times$ & - & $\times$ & - & - & - \\
\hline Ma et al. (2019) & Dao He Old Block inTaizhou (China) & $\times$ & - & - & $\times$ & $\times$ & $\times$ \\
\hline Berkovic et al. (2012) & Single courtyards in Beer-Sheba (Israel) & $\times$ & - & - & $\times$ & $\times$ & - \\
\hline Del Rio et al. (2019) & Dwelling in Kumagaya (Japan) & $\times$ & - & - & - & $\times$ & $\times$ \\
\hline Abdulkareem (2016) & Traditional house in Baghdad (Irak) & $\times$ & - & - & - & $\times$ & - \\
\hline Du et al. (2014) & Yang's House (China) & $\times$ & - & - & - & - & $\times$ \\
\hline Al-Masri and Abu-Hijleh (2012) & Simulated buildings in Dubai (EAU). Review & $\times$ & - & - & - & - & $\times$ \\
\hline Moonen et al. (2011) & Simulated coutyards & $\times$ & - & - & - & - & - \\
\hline Yang et al. (2012) & Simulated coutyard & $\times$ & - & - & - & - & $\times$ \\
\hline Muhaisen and Gadi, (2006) & Simulated buildings in Rome (Italy) & $\times$ & - & - & - & - & - \\
\hline Almhafdy et al. (2015b) & Different courtyards building (model) & $\times$ & - & - & - & - & - \\
\hline Almhafdy et al. (2013) & Hospitals (Malaysia) & - & $\times$ & - & - & $\times$ & - \\
\hline Taleghani et al. (2014ca) & Campus in Portland (USA) and Delf (Netherlands) & - & - & $\times$ & - & $\times$ & $\times$ \\
\hline Taleghani (2018) & Courtyard building in Portland (USA). Review & - & - & $\times$ & - & $\times$ & $\times$ \\
\hline Shahidan et al. (2012) & Malay places (Malaysia) & - & - & $\times$ & - & $\times$ & $\times$ \\
\hline Taleghani et al. (2014a) & Dwellings in Amsterdam (Netherlands) & - & - & $\times$ & - & - & - \\
\hline Shashua-Bar et al. (2009) & Courtyard in Negev Highland (Israel) & - & - & - & $\times$ & $\times$ & $\times$ \\
\hline Taleghani et al. (2014cb) & Blocks buildings (Netherlands) & - & - & - & - & $\times$ & $\times$ \\
\hline Salata et al. (2015) & Cloister in Rome (Italy) & - & - & - & - & - & $\times$ \\
\hline
\end{tabular}


Almhafdy, Norhati, Sh Ahmad, \& Yahya, 2015a; Almhafdy, Ibrahim, Ahmad, \& Yahya, 2015b; Berkovic, Yezioro, \& Bitan, 2012; Cantón, Ganem, Barea, \& Llano, 2014; Cindel, Yung, Norhayati, \& Norafida, 2018; Del Rio, Asawa, Hirayama, Sato, \& Ohta, 2019; Du, Bokel, \& van den Dobbelsteen, 2014; Ghaffarianhoseini, Berardi, \& Ghaffarianhoseini, 2015; Guedouh \& Zemmouri, 2017; Huang, Hamza, Lan, \& Zahi, 2016; Jihad \& Tahiri, 2016; Ma, Fukuda, Zhou, Gao, \& Wang, 2019; Manioğlu \& Oral, 2015; Martinelli \& Matzarakis, 2017; Moonen, Dorer, \& Carmeliet, 2011; Muhaisen \& Gadi, 2006a; Muhaisen \& Gadi, 2006b; Muhaisen, 2006; Nasrollahi, Hatami, Khastar, \& Taleghani, 2017; Qaid \& Ossen, 2015; Rodríguez-Algeciras, Tablada, Chaos-Yeras, De la Paz, \& Matzarakis, 2018; Rojas, Galán-Marín, \& Fernández-Nieto, 2012; Rojas-Fernández, Galán-Marín, Roa-Fernández, \& Rivera-Gómez, 2017; Soflaei, Shokouhian, \& Mofidi Shemirani, 2016; Soflaei, Shokouhian, Abraveshdar, \& Alipour, 2017; Taleghani et al., 2014b; Taleghani, Kleerekoper, Tenpierik, \& van den Dobbelsteen, 2015; Toe \& Kubota, 2015; Xu, Luo, Wang, Hong, \& Fu, 2018; Yang, Li, \& Yang, 2012; Yaşa \& Ok, 2014; Zamani et al., 2018). Solar orientation is another determining parameter in the potential efficiency of courtyards with respect to specific thermal conditions (Almhafdy et al., 2015a; Cantón et al., 2014; Cindel et al., 2018; Ghaffarianhoseini et al., 2015; Guedouh \& Zemmouri, 2017; Huang et al., 2016; Manioğlu \& Oral, 2015; Muhaisen \& Gadi, 2006a; Muhaisen, 2006; Nasrollahi et al., 2017; Qaid \& Ossen, 2015; Rodríguez-Algeciras et al., 2018; Rojas et al., 2012; Soflaei et al., 2016; Soflaei et al., 2017; Taleghani et al., 2014b; Taleghani et al., 2015; Toe \& Kubota, 2015; Xu et al., 2018; Zamani et al., 2018). Outdoor temperature and courtyard location in a specific climate is a key factor, due to better courtyard behavior in hot climates. In fact, most published research deals with case studies in warm regions of the planet (Aldawoud, 2008; Ghaffarianhoseini et al., 2015; Guedouh \& Zemmouri, 2017; Huang et al., 2016; Jihad \& Tahiri, 2016; Martinelli \& Matzarakis, 2017; Muhaisen, 2006; Nasrollahi et al., 2017; Rodríguez-Algeciras et al., 2018; Rojas et al., 2012; Rojas-Fernández et al., 2017; Shahidan, Jones, Gwilliam, \& Salleh, 2012; Soflaei et al., 2017; Taleghani et al., 2014a; Taleghani, Tenpierik, van den Dobbelsteen, \& Sailor, 2014ca; Taleghani et al., 2015; Taleghani, 2018; Xu et al., 2018; Yaşa \& Ok, 2014; Zamani et al., 2018). Other variables such as shading (Berkovic et al., 2012; Cindel et al., 2018; Huang et al., 2016; Ma et al., 2019; Shashua-Bar, Pearlmutter, \& Erell, 2009Soflaei et al., 2017; Zamani et al., 2018), vegetation (Abdulkareem, 2016; Almhafdy, Ibrahim, Ahmad, \& Yahya, 2013; Berkovic et al., 2012; Cantón et al., 2014; Cindel et al., 2018; Del Rio et al., 2019; Ghaffarianhoseini et al., 2015; Ma et al., 2019; Shahidan et al., 2012; Shashua-Bar et al., 2009; Taleghani et al., 2014ca; Taleghani, Tenpierik, van den Dobbelsteen, \& Sailor, 2014cb; Taleghani, 2018; Toe \& Kubota, 2015; Zamani et al., 2018) or albedo (Al-Masri \& Abu-Hijleh, 2012; Cindel et al., 2018; Del Rio et al., 2019; Du et al., 2014;
Ghaffarianhoseini et al., 2015; Huang et al., 2016; Ma et al., 2019; Manioğlu \& Oral, 2015; Martinelli \& Matzarakis, 2017; Salata, Golasi, Vollaro, \& Vollaro, 2015; Shahidan et al., 2012; Shashua-Bar et al., 2009; Taleghani et al., 2014b; Taleghani et al., 2014ca; Taleghani et al., 2014cb; Taleghani, 2018; Toe \& Kubota, 2015; Yang et al., 2012; Zamani et al., 2018) have also been studied since they can contribute significantly to the thermal tempering of the patio. Table 1 shows a simple review of the literature that addresses the variables that influence the tempering effect of the patio. Even though all aspects related to this topic have generated attention in the scientific community, it can be appreciated that studies that include the parameters related to geometry, orientation and location in a precise thermal environment are the most widely represented in this field of research.

The main focus of this paper was to study the impact of the courtyard AR and thermal parameters, such as diurnal thermal range (DTR) and maximum outdoor temperature (MOT), assessed on their combined potential effectiveness as thermal tempering tools. It is essential that modification of any of these items in the interaction modeling includes the courtyard's main common specifications. Therefore, a wide range of case studies that include all these variables were monitored to determine courtyard tempering behavior in locations with specific climatic severity in the warmest periods of the year. Basically, the study aimed to review the effectiveness of certain passive cooling strategies that have proved useful in today's architecture. Courtyard tempering potential is especially relevant in reducing climate change impact and the cost of the average lifespan of buildings by reducing operational energy needs (Abdulkareem, 2016). Previous studies show that the manipulation of courtyard configuration and its orientation impact its microclimate modifying ability (Almhafdy et al., 2015a; Almhafdy et al., 2013). These benefits are particularly valuable for future outdoor thermal comfort assessment in warm regions not only on a building scale but in urban design and planning (Fong, Aghamohammadi, Ramakreshnan, Sulaiman, \& Mohammadi, 2019; Nakano, 2015). The major novelty of the present study is the assessment of thermal factors not previously considered combined, namely, MOT and DTR with courtyard geometry (AR) in a wide range of cases study in order to determine thermal behavior patterns within the courtyards.

\section{Materials and methods}

\subsection{Study site location, descriptions and future climatic scenario}

The present study was carried out in southern Spain, in cities located in the western part of two Spanish regions, Andalusia and Extremadura. The cities were selected on the basis of their climatic conditions, these being the warmest climate sites in coastal and noncoastal locations. Spanish climate zoning (Fig. 1) is categorized in the
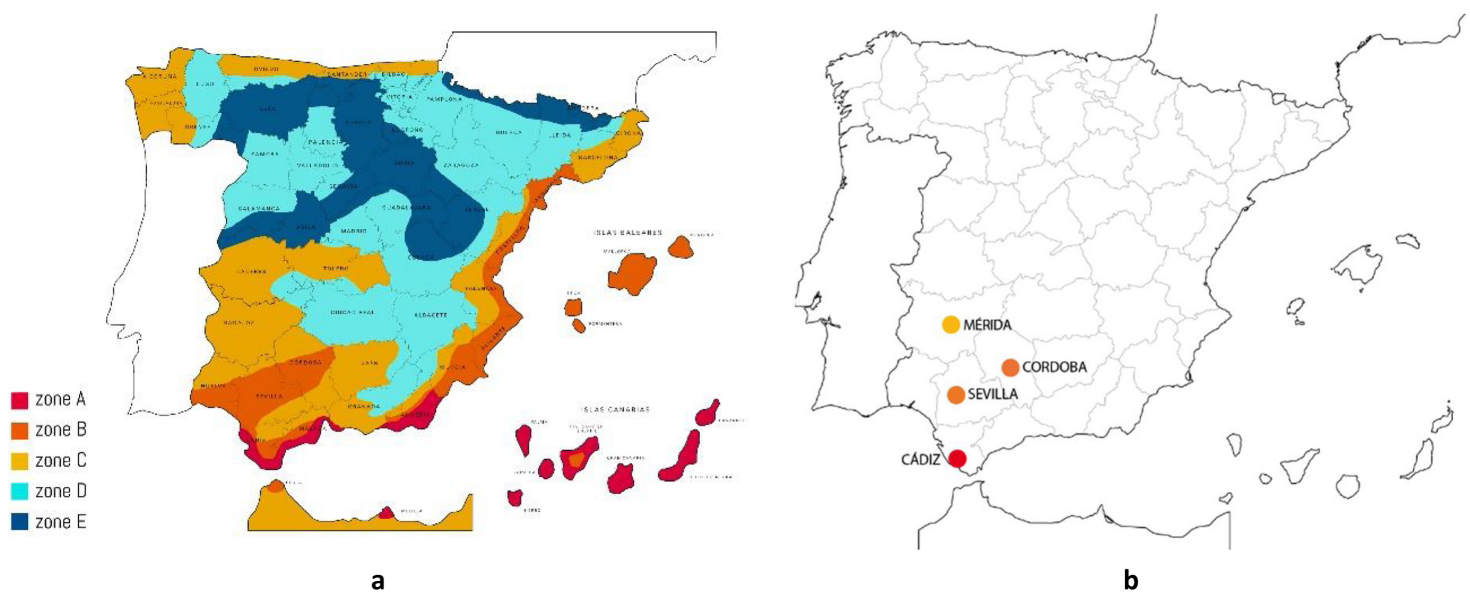

Fig. 1. (a) Spanish climate zones according to CTE (2019). (b) Case study location. 
Código Técnico de la Edificación Documento Básico de Ahorro Energético (CTE-DB-HE) (CTE, 2019) by the letters A to E, which reflects winter climate severity, and numbers 1 to 4, for summer climate severity; thus, A1 represents a very mild climate in terms of thermal changes. Accordingly, courtyards can be selected from the same, or different, climate zones depending on the comparison to be made. In this case, taking into account that the main research goal was to show the interconnection between the maximum temperature ranges and courtyard thermal tempering potential, three climate zones were chosen, all within the maximum summer climate severity zones but distinguishing between the warm-dry interior and the warm-humid coastal climates.

Considering Spain's climate zoning, as well as the average annual temperature forecasts for Andalusia, the interior cities of Merida (Extremadura), with climate zone C4, Seville and Cordoba (Andalusia), B4, and the province of Cadiz (Andalusia), A3, as an example of a coastal zone, were selected (Fig. 1). All the sites chosen were classified as 3 or 4, the maximum severity range, with a very hot summer climate. The alphanumeric code of the climate zones selected reflects the fact that the climate severity in the city of Merida is average in winter and very high in summer, while in the provinces of Seville and Cordoba it is low in winter and very high in summer; in the province of Cadiz it is very low in winter and medium-high in summer. The maximum and minimum absolute temperatures in the locations of the courtyard studied are expressed below (Table 2). These temperatures were obtained from the AEMET historical climatology database (AEMET, 2019), which acquires such records from meteorological stations located on the cities suburbs, which means that they are not affected by the Urban Heat Island (UHI) phenomenon. Outdoor temperatures used in the present work are more specific local records obtained from portable meteorological stations located on the roofs of the buildings studied, so they are generally affected by UHI.

The DTR is the difference between the maximum and minimum temperatures on a given day according to the equation:

$T_{\max }-T_{\min }=\operatorname{DTR}\left({ }^{\circ} \mathrm{C}\right)$

Diurnal temperature distributions are further complicated by local topographic effects such as coast, mountains and other significant geographical features, where increased or decreased cloudiness with altitude can modify diurnal ranges. Urbanized areas often show a narrower DTR than nearby rural areas, in fact there is a link between DTR and UHI, been possible to measure this parameter by means of the DTR variations between a city and its surroundings. The use of the globalaverage DTR as an index of climate change and variability was evaluated by using observations and climate model simulations representing unforced climate variability and anthropogenic climate change (AEMET, 2019; Easterling, Horton, \& Jones, 1997; Vinnarasi, Dhanya, Chakravorty, \& AghaKouchak, 2017). Understanding the evolution of DTR is crucial because it influences human and environmental health (Lee, Bell, \& Gasparrini, 2018b; Lee, Kim, Honda, \& Kim, 2018a). Accordingly, the study of the DTR variation between the outdoor and courtyard temperature in a specific climate zone is essential for evaluating the courtyard thermal tempering potential throughout the day.

Regarding the distribution patterns across Andalusia, a dominant feature of the DTR in the region is the high range $\left(18-20^{\circ} \mathrm{C}\right)$ in the west-north zones, especially the Guadalquivir valley and Sierra Morena, under warm semi-arid Continental-Mediterranean conditions. According to the Köppen classification, this region studied is located in an area of category Csa, with warm temperature climate and dry summer and especially hot (Kottek, Grieser, Beck, Rudolf, \& Rubel, 2006). These generally high ranges in the summer months are associated with scarce rainfall, with this dry period normally lasting 4-5 months. By contrast, in the eastern and western coastal zones, the DTR is within the low range $\left(10-16^{\circ} \mathrm{C}\right)$. A seasonal shift in the zones with high-temperature ranges is evident in the interior. Highest ranges trend north-south in summer months, but shift to a more west-east alignment in winter months (Junte, 2019). Below a seasonal DTR ranging for the climatic zones where the studied courtyards are located is shown (Table 3).

With data from the Intergovernmental Panel on Climate Change (IPCC), Fig. 2.1 shows the average thermal forecasts for Andalusia in the 21st century (IPCC, 2019). Data reflect that the entire region will be affected by climate change but, while the impact on the interior areas will be especially severe, the coast will experience a gentler thermal evolution. In the interior, the increase in heat waves will be remarkable and will exceed the current duration (Fig. 2.2). Furthermore, not only the average monthly temperatures but also the thermal peaks in the warm seasons of the year will have a greater impact on the population. Therefore, a fundamental aspect of this research was the study of courtyard performance both in the interior and coastal areas of

Table 2

Maximum and minimum absolute temperatures for the locations of the courtyards studied.

\begin{tabular}{|c|c|c|c|c|c|c|c|c|c|c|c|c|}
\hline \multicolumn{13}{|c|}{ Merida } \\
\hline & Jan & Feb & Mar & Apr & May & Jun & Jul & Aug & Sep & Oct & Nov & Dec \\
\hline Max & 23.2 & 29 & 30 & 33.2 & 38.6 & 43.4 & 45.4 & 44.8 & 43.7 & 35.8 & 29.2 & 25.6 \\
\hline Min & -7.2 & -6.6 & -2.8 & -1.2 & 4 & 6.8 & 9.6 & 9 & 6 & -2.2 & -4.4 & -7 \\
\hline \multicolumn{13}{|c|}{ Seville } \\
\hline & Jan & Feb & Mar & Apr & May & Jun & Jul & Aug & Sep & Oct & Nov & Dec \\
\hline Max & 24.2 & 28 & 32.9 & 35.4 & 40.8 & 45.2 & 46.6 & 45.9 & 44.8 & 36.6 & 31.2 & 24.5 \\
\hline Min & -4.4 & -5.5 & -2 & 1 & 3.8 & 8.4 & 11.4 & 12 & 8.6 & 2 & -1.4 & -4.8 \\
\hline \multicolumn{13}{|c|}{ Cordoba } \\
\hline & Jan & Feb & Mar & Apr & May & Jun & Jul & Aug & Sep & Oct & Nov & Dec \\
\hline Max & 22.9 & 27.8 & 33 & 34 & 41.2 & 45 & 46.9 & 46.2 & 45.4 & 36 & 29.7 & 23.8 \\
\hline Min & -8.2 & -5 & -4.2 & 0.2 & 2.4 & 7 & 11 & 11 & 6 & 1 & -3.6 & -7.8 \\
\hline \multicolumn{13}{|c|}{ Cadiz } \\
\hline & Jan & Feb & Mar & Apr & May & Jun & Jul & Aug & Sep & Oct & Nov & Dec \\
\hline Max & 22.5 & 25.3 & 29 & 31.4 & 36.5 & 37.6 & 40 & 43 & 37.8 & 31.5 & 27.6 & 23.6 \\
\hline Min & 0.2 & -1 & 3 & 6.5 & 9.2 & 11 & 16.6 & 15.6 & 12.6 & 8 & 4.6 & 1.5 \\
\hline
\end{tabular}


Table 3

Seasonal DTR ranging according to Climate Zoning.

\begin{tabular}{lccc}
\hline Season & \multicolumn{4}{c}{ DTR ranging according to Climate Zoning $\left({ }^{\circ} \mathrm{C}\right)$} \\
\cline { 2 - 4 } & C4 & B4 & A3 \\
\hline $\begin{array}{l}\text { Spring and/or autumn close to } \\
\text { summer }\end{array}$ & $>20$ & $>20$ & $16-20$ \\
$\begin{array}{l}\text { Summer } \\
\text { Summer (heat wave) }\end{array}$ & $\begin{array}{c}16-20 \\
>20\end{array}$ & $\begin{array}{c}16-20 \\
>20\end{array}$ & $\begin{array}{c}<16 \\
16-20\end{array}$ \\
\hline
\end{tabular}

Andalusia, distinguished by higher DTR and MOT more remarkably in the interior of the region.2.2. The set of case studies.

The AR is defined as the ratio of height to width of the courtyards. The equation for $\mathrm{AR}$ is expressed as follow:

$A R=\frac{H}{W}$

Previous research related temperature distribution inside the courtyard to the flow pattern, directly influenced by the courtyard AR, characterizing the air changes per hour (ACH) at intermediate sections and at the top of the courtyard (Alvarez, Sanchez, \& Molina, 1998). In this work, we selected a range of case studies with an AR interval of between near 0 and 7 to know the importance of this factor. The 20 courtyards that constitute this set of case studies were each monitored for a two-week period in the cities of Merida (Badajoz, Spain, $38^{\circ} 54^{\prime}$ $57^{\prime \prime} \mathrm{N} 6^{\circ} 20^{\prime} 37^{\prime \prime} \mathrm{W}$, elevation $229 \mathrm{~m}$ above sea level), Seville (Seville, Spain, $37^{\circ} 22^{\prime} 58^{\prime \prime} \mathrm{N} 5^{\circ} 58^{\prime} 23^{\prime \prime} \mathrm{W}$, elevation $16 \mathrm{~m}$ above sea level), Cordoba (Cordoba, Spain, 37 $53^{\prime} 30^{\prime \prime} \mathrm{N} 4^{\circ} 46^{\prime} 22^{\prime \prime} \mathrm{W}$, elevation $106 \mathrm{~m}$

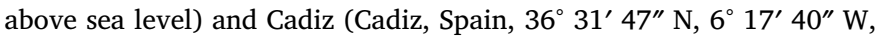
elevation $11 \mathrm{~m}$ above sea level); all the courtyards were located inside buildings, which were both residential and public. With the aim of reducing the number of variables, courtyards with the same characteristics in terms of albedo and orientation have been selected. All the selected case studies have been taken from the centers of the cities where all the surroundings present similar height and orientation. The courtyards are described in Table 4 and more detailed in the Supplementary Material, Table A.1.

\subsection{Field measurement methodology}

This study assessed building courtyard alternatives with different AR. Monitoring and recording campaigns were carried out for two years to study the thermal performance of 20 different courtyards as individual case studies. In order to evaluate the performance of the buildings, with their different courtyard shapes, the monitoring methodology followed a previously developed protocol (López-Cabeza, Galán-Marín, Rivera-Gómez, \& Roa-Fernández, 2018). The minimumrecorded interval spanned two weeks in order to facilitate the data analysis. From these periods, the final data evaluated in the study have been obtained excluding meteorological anomalies that were not representative of the local seasonal climatology or variables such as the wind influence that excessively complicate the analysis of the results. Outdoor temperature was recorded by a weather station located on the roof of each building, and the courtyards' indoor temperature by humidity and temperature recording devices placed at different heights.

The results of the campaigns were analyzed by outcome graphs showing the outdoor and courtyard temperatures evolution (Fig. 3). In addition, even though the wind was not a significant factor in the locations selected, it was recorded in order to understand sudden thermal changes that may occur. Outdoor climate data were logged by a portable weather station model, PCEFWS. Meteorological data provided by the Spanish Meteorological Agency (AEMET) were also obtained for each location (AEMET, 2019). The values inside the courtyards were recorded by TESTO $174 \mathrm{H}$ data loggers at the lower level (temperature and humidity), and the TESTO $174 \mathrm{~T}$ model (temperature), placed at different medium and upper levels in order to study courtyard stratification. Following the aforementioned protocol (López-Cabeza et al., 2018), data loggers were protected with radiation shields in order to minimize this effect. Not only the data logger positioning but also sheltering was considered in anticipation of possible direct solar

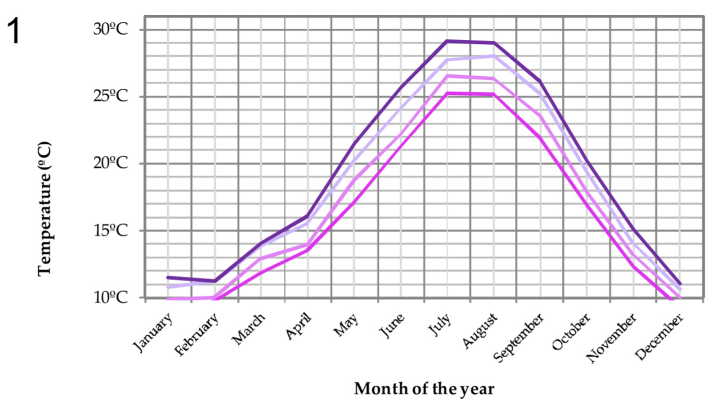

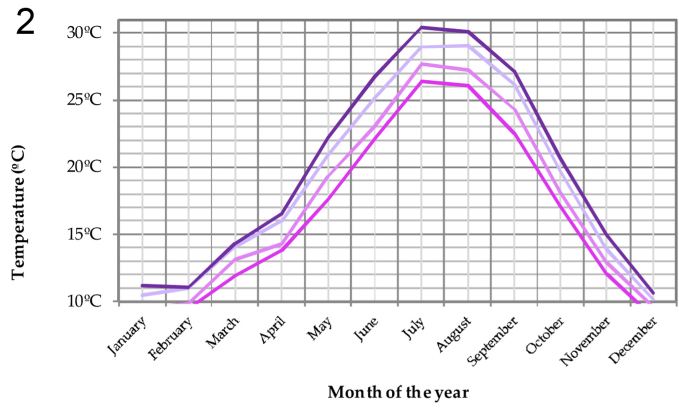

a

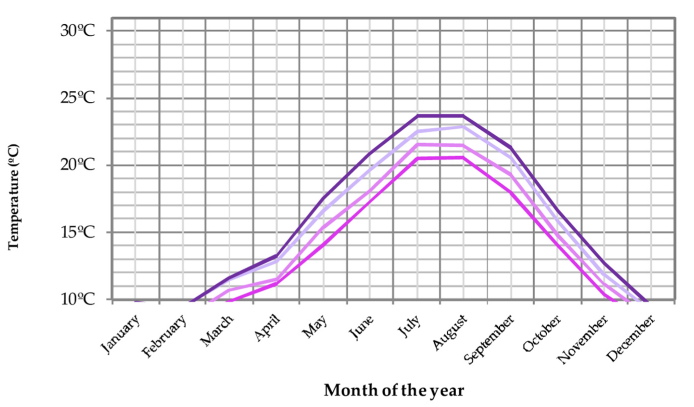

b

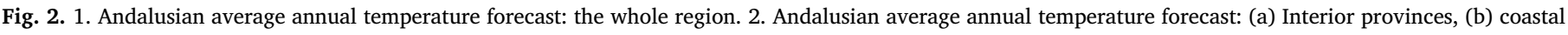
provinces. 
Table 4

Overview of the schematic plan and section for twenty courtyards analyzed as case studies.

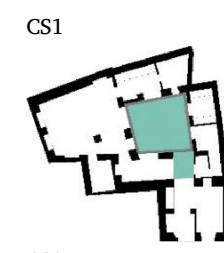

CS3
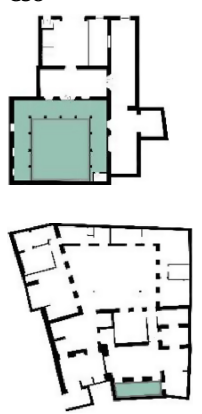

CS7
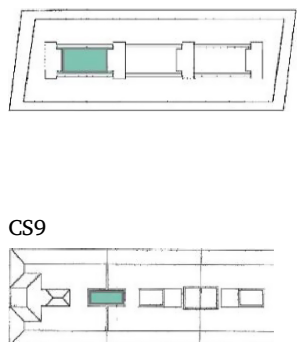

CS11

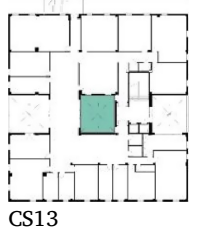

CS13

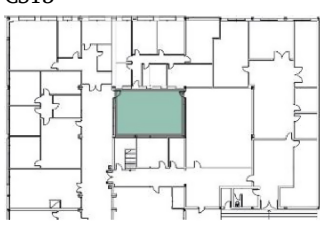

CS15
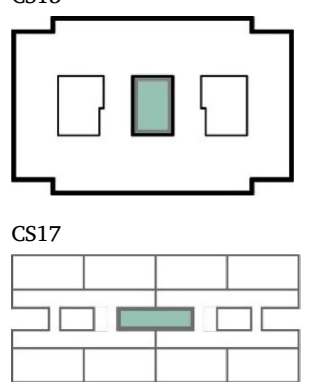
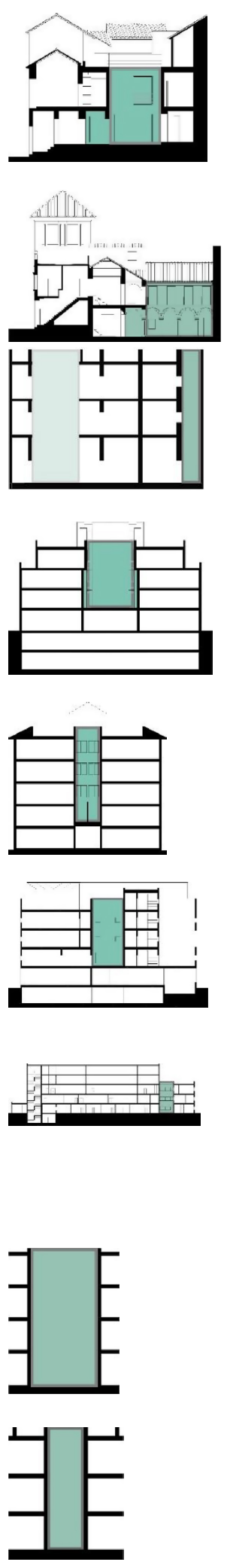

CS2
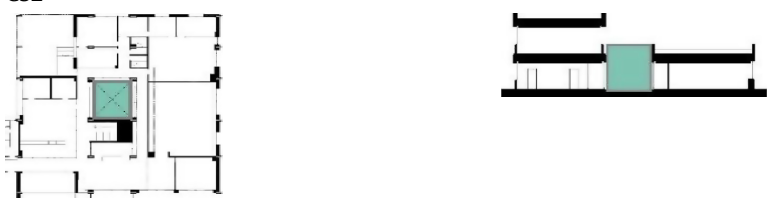

CS4
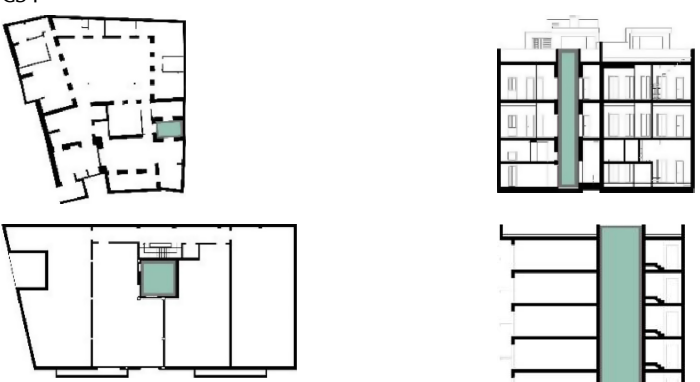

CS8
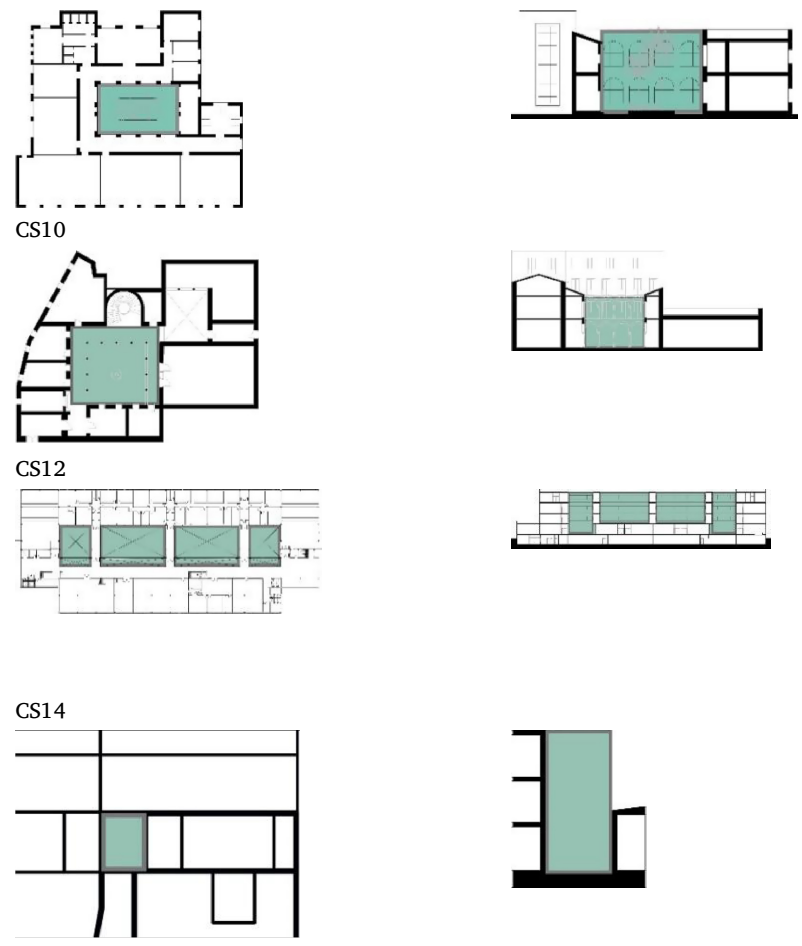

CS16
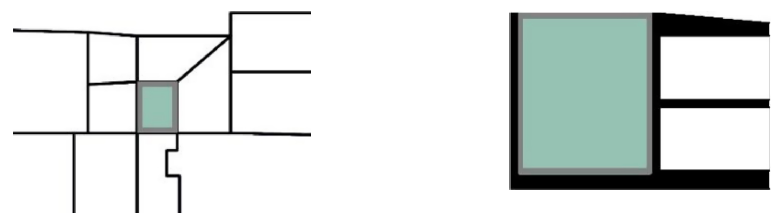

CS18

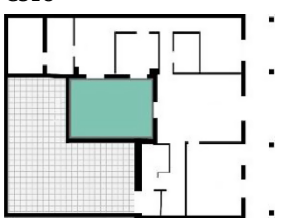

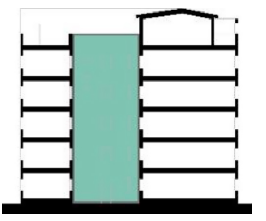

(continued on next page) 

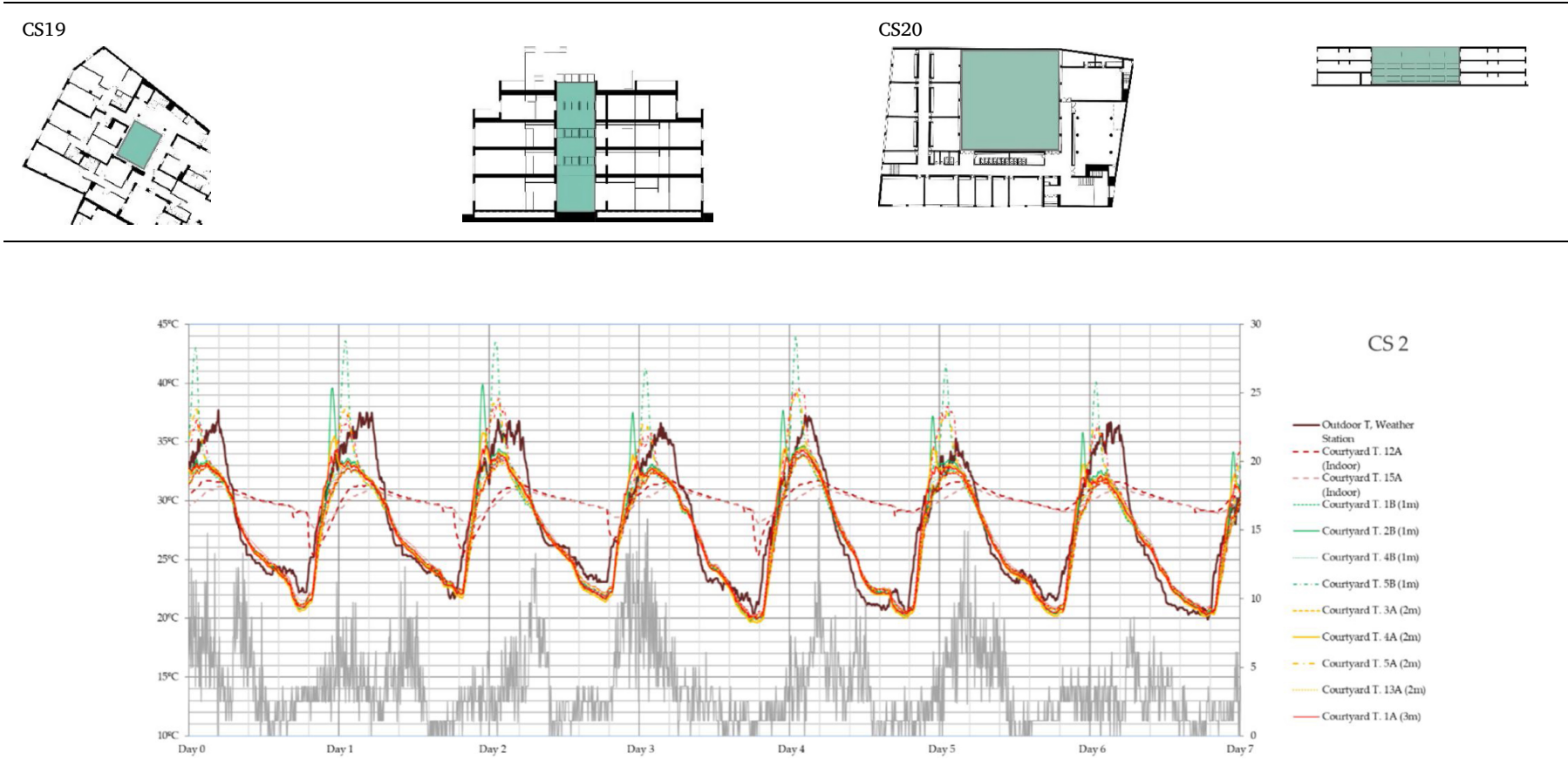

Fig. 3. Example of the CS2 courtyard monitoring results graph.

radiation and thermal peaks. Thermal differences between outdoor and courtyard temperatures were calculated following this monitoring protocol; the latter was obtained at different heights in sections of $3 \mathrm{~m}$ starting from a first sensor placed $1 \mathrm{~m}$ above the courtyard pavement. This was done in order to verify the thermal stratification of the air contained in the courtyard.

In this research, the central courtyard was selected as the common courtyard building type, with equal albedo and orientation conditions for all case studies. The main assumptions governing the courtyard building alternatives were as follows: The courtyard shape factors evaluated as AR varied between 0.19 and 7.10, with sequential intervals to compare the alternatives to different courtyard shapes. This AR ranging was based on a previous study (Yaşa \& Ok, 2014) that involved over 16,500 courtyards. In that research, using Geographical Information Systems (GIS), the most representative courtyards geometries in the studied cities were identified. For each courtyard building type, the courtyard floor area ranged from $6.4 \mathrm{~m}^{2}$ to $816 \mathrm{~m}^{2}$ with sequential intervals to compare the building types with different areas. Courtyards were monitored during different seasons of the year, with diverse climate thermal patterns (CTP) from average to maximum temperatures, to evaluate outdoor temperature influence on courtyard thermal performance.

\section{Results and discussion}

In the present study, outdoor temperature variations represent the main point of comparison. Thermal evolution, measured by MOT and DTR, and its interaction with the courtyard shape measured as AR, established the assessment criteria. The results obtained are, therefore, represented by different CTPs, from the average to the maximum temperatures respectively, collected in the warm and hot seasons for each geographical location.

\subsection{Courtyard behavior}

Following the aforementioned monitoring protocol (López-Cabeza

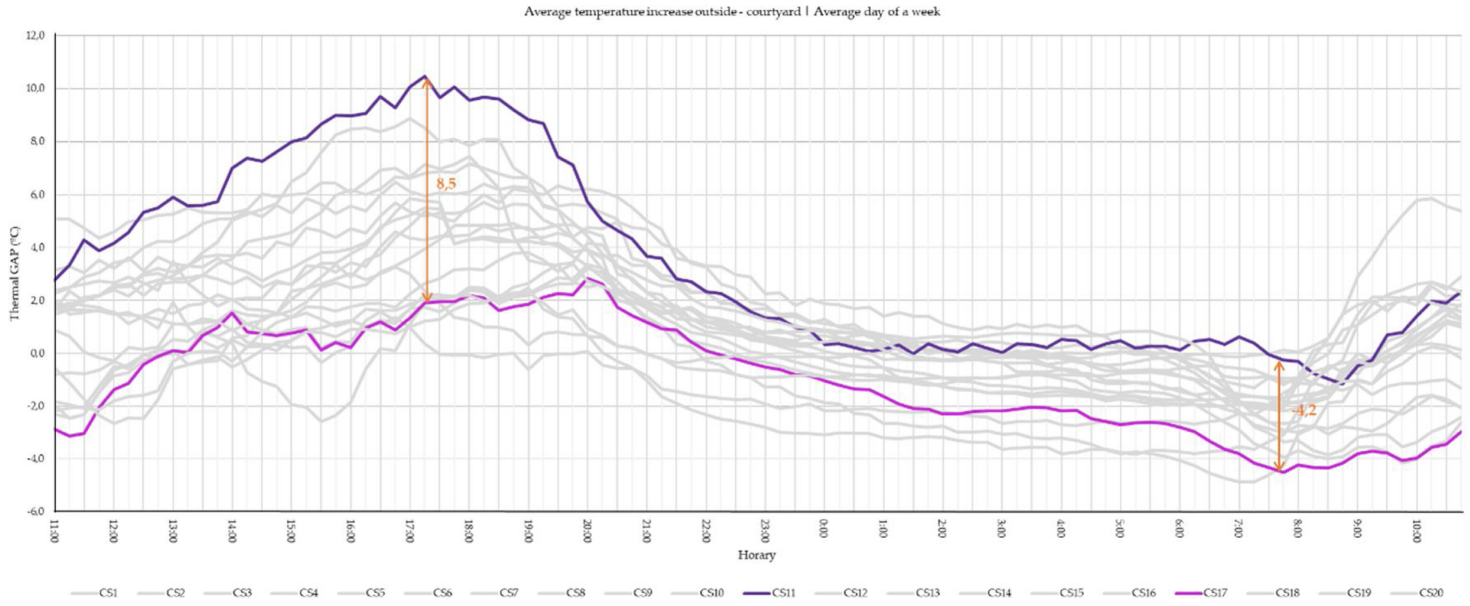

Fig. 4. TG representation contrasting all the courtyards temperatures versus the outdoor ones. 
et al., 2018), thermal Gap (TG) between the courtyard temperature (CT) and the outdoor air temperature (OT) was calculated as follows:

$T G=O T-C T$

Overall, TG is the thermal difference (expressed in ${ }^{\circ} \mathrm{C}$ ) of the courtyard with regard to the outdoor temperature at any time of the day. Since the main research aim was to obtain the courtyard efficiency in terms of thermal tempering in a warm climate scenario, for the TG calculation the MOT value was taken as a reference to compare with the meanwhile CT as follows:

$T G_{M O T}=M O T-C T_{M O T}$

As observed in the graph (Fig. 3), the outdoor and courtyard data logger temperature monitoring results were plotted simultaneously to verify temperature evolution over seven days.

TG values between outdoor and courtyard temperature were represented for a 24-hour cycle. In Fig. 4, each day represents the mean TG of a set of seven days monitoring campaign. The courtyard mean temperature was obtained following a previously developed protocol for both, the data logger placement and the interpretation and discretization of the thermal values obtained (López-Cabeza et al., 2018). As seen when superimposing the 20 case studies, the maximum TG difference between courtyards with diverse geometrical configurations is bigger during the hottest hours of the day.

With the aim of ensuring that the evaluation of the data obtained was more representative of the courtyards real thermal performance, a period of seven days with analogous climatic conditions was selected for each case study, calculating the mean TG per hour (Appendix, Table A.2) and reflecting this value in the corresponding graph (Fig. 4).

The graph overview corroborates the regular trend of courtyard tempering performance according to which, when daytime temperatures begin to rise, TG is positively heightened, while, when night temperatures drop, TG is negative. This happens because of the comparatively slower temperature loss inside the courtyard at night. In short, it can be inferred that the thermal regulation provided by a passive architectural design strategy such as the courtyard offers a greater level of comfort, tempering the maximum thermal records during the warmest part of the day.

\subsection{Comparison of thermal mitigation in three climatic scenarios}

The verification of courtyard thermal tempering peaks in the hottest hours of the day was taken as a starting point for courtyard performance analysis as a passive cooling system. In order to assess comprehensively the relationship between courtyard thermal tempering potential with respect to the MOT, the reference values of this outdoor maximum temperature were sequenced in three CTPs, corresponding to the intermediate and characteristic warm-season maximum temperature values for the three locations studied (Table 5).

As shown in Fig. 5, the thermal difference between the maximum courtyard temperature values corresponding to the MOT is organized across three thermal ranges, these thermal values correspond to the mean statistical climatic records for the hottest days of spring and/or autumn (CTP $<35^{\circ} \mathrm{C}$ ), summer (CTP $35-41^{\circ} \mathrm{C}$ ) and a summer during a heat wave (CTP $>41^{\circ} \mathrm{C}$ ) in the locations considered. This last CTP was included due to the influence of the increasingly common summer heat waves on urban overheating and building thermal-energy performance (Pyrgou, Castaldo, Pisello, Cotana, \& Santamouris, 2017). This case study distribution reveals that the TG difference depends on the season and climate zone in which they are located. The CTP allocation of the different CSs depends on the possibility of the specific locations in the climatic zones studied to cover all the CTPs: CTP $>41^{\circ} \mathrm{C}$, CTP $=35-41{ }^{\circ} \mathrm{C}$ and CTP $<35^{\circ} \mathrm{C}$. This is only achievable for C4 and B4; having $\mathrm{A} 3$ a more limited annual thermal range. Additionally, the displayed results obey to those days in which it was also possible to ignore wind speed because this parameter was smaller than 1 in the
Beaufort scale alongside the period considered for the analysis.

For each CTP, courtyards with different AR were evaluated. For each case study, the left column of the graphs shows the MOT registered during a selected monitoring week, while the right column shows the final value for the courtyards temperature corresponding to these outdoor temperature measurements.

TG between outdoor and courtyard temperatures are shown in Celsius for each case study in the three CTPs analyzed. For case studies evaluated in the CTP $>41{ }^{\circ} \mathrm{C}$ range (Supplementary Material, Table A.3), there is a maximum TG up to $15.3^{\circ} \mathrm{C}$ for $\mathrm{CS} 4$, and a minimum of $8.8^{\circ} \mathrm{C}$ in CS 3 ; for case studies in the CTP $35-41{ }^{\circ} \mathrm{C}$ range (Supplementary Material, Table A.4), there is a maximum TG up to $11.9^{\circ} \mathrm{C}$ for CS 11 , and a minimum of $4.4^{\circ} \mathrm{C}$ in CS 3 and, for case studies evaluated in the CTP $<35^{\circ} \mathrm{C}$ range (Supplementary Material, Table A.5), there is a maximum TG up to $6.9^{\circ} \mathrm{C}$ for CS 13 , and a minimum of $3.1^{\circ} \mathrm{C}$ in CS 18 . All this corroborates that MOT is a fundamental value directly related to courtyard thermal tempering performance.

All the factors that influence courtyard thermal performance have been widely studied. In light of the existing literature, the results shown in the previous tables can be analyzed. Although the maximum and minimum TGs are ordered in accordance with the different CTPs, it is not always true for all the case studies that the highest TG corresponds to the highest MOT. Considering that, in the case studies selection, aspects related to orientation, cities layout or vegetation have been unified, this indicates that factors such as geometry or AR are also relevant courtyard characteristics, and have considerable influence on courtyard thermal performance.

\subsection{Outdoor temperature effect on the courtyard DTR}

Despite being a determining factor in courtyard thermal performance, the MOT analysis only establishes a specific parameter within a daily cycle. If the aim is to know the outdoor temperature effect during a whole-day cycle in the courtyard thermal tempering performance, a comparative parallel study is required that also considers the DTR. The following graphs (Fig. 6) show the DTR values for a whole-day cycle in the three CTPs established above. For each case study, the left column represents the outdoor DTR while the right column represents the courtyard DTR. The CTP allocation for the different CSs is the same as proposed in Fig. 5. In the graphs, the DTR ranging mentioned (Table 2) almost exactly corresponds with the courtyards locations in the climatic zones studied.

The outdoor and courtyard DTR appraisal shows different results regarding the three CTPs analyzed. DTR gap was calculated by means of the net difference between the outdoor DTR and the courtyard DTR, according to the following equation:

\section{DTR gap = Outdoor DTR - Courtyard DTR}

As shown in Fig. 6, for case studies evaluated in the CTP $>41{ }^{\circ} \mathrm{C}$ range (Supplementary Material, Table A.6), there is a maximum DTR gap of up to $17.2^{\circ} \mathrm{C}$ for CS 5, and a minimum DTR gap of $7.7^{\circ} \mathrm{C}$ in CS 3; for case studies in the CTP $35-41{ }^{\circ} \mathrm{C}$ range (Supplementary Material, Table A.7), there is a maximum DTR gap of up to $12.8^{\circ} \mathrm{C}$ for CS 11 , and a minimum DTR gap of $5.8^{\circ} \mathrm{C}$ in CS 7 and, for case studies evaluated in the CTP $<35^{\circ} \mathrm{C}$ range (Supplementary Material, Table A.8), a maximum DTR gap of up to $8.6^{\circ} \mathrm{C}$ for CS 17 , and a minimum DTR gap of

\section{Table 5}

CTPs prevalence regarding the different seasons and climatic zones studied.

\begin{tabular}{llll}
\hline Season & \multicolumn{2}{l}{ Climate zoning } & \\
\cline { 2 - 4 } & C4 & B4 & A3 \\
\hline Spring and/or autumn & CTP $<35^{\circ} \mathrm{C}$ & CTP $<35^{\circ} \mathrm{C}$ & - \\
Summer & CTP $35-41^{\circ} \mathrm{C}$ & CTP $35-41^{\circ} \mathrm{C}$ & CTP $<35^{\circ} \mathrm{C}$ \\
Summer (heat wave) & CTP $>41^{\circ} \mathrm{C}$ & CTP $>41{ }^{\circ} \mathrm{C}$ & CTP $35-41^{\circ} \mathrm{C}$
\end{tabular}




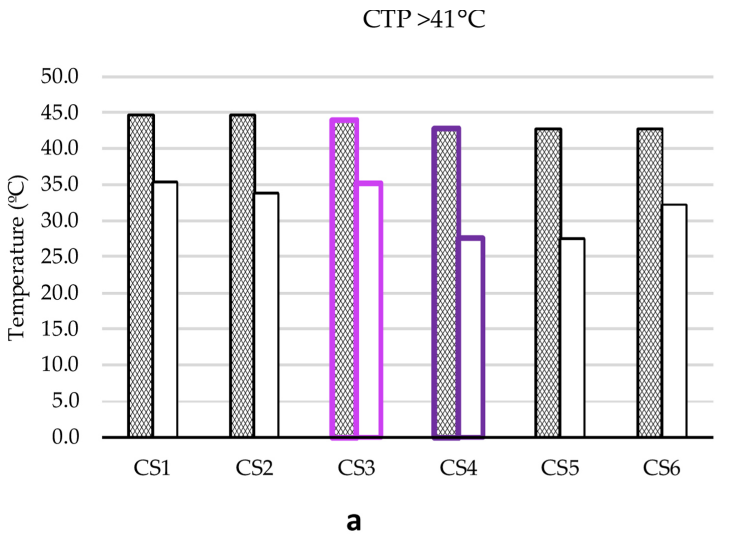

CTP $35-41^{\circ} \mathrm{C}$

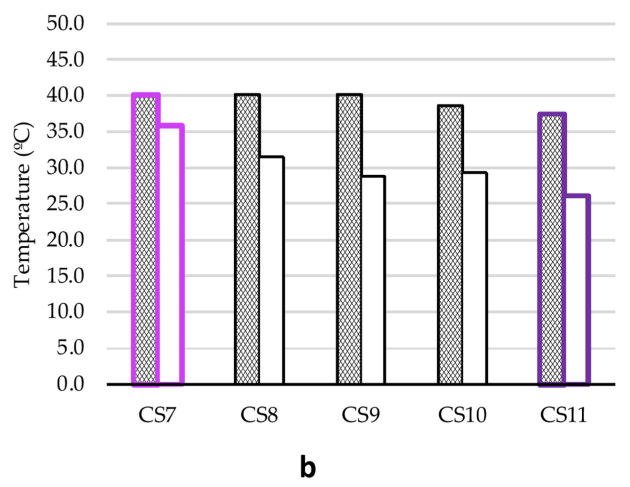

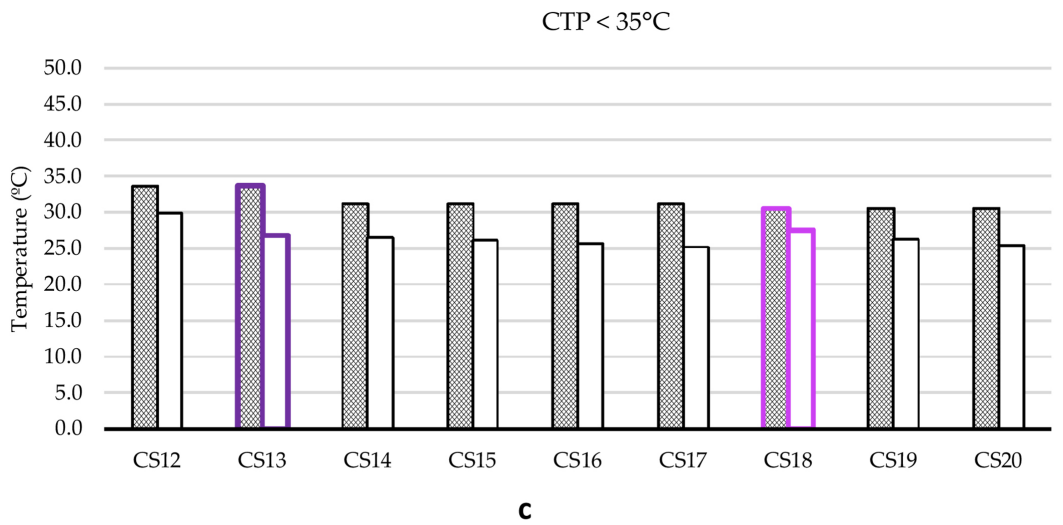

MOT

$\square \quad$ Courtyard $T_{\max }$

Maximum TG

Minimum TG

Fig. 5. Outdoor versus courtyard thermal difference at the daily MOT. (a) CTP $>41{ }^{\circ} \mathrm{C}$, (b) CTP $35-41{ }^{\circ} \mathrm{C}$ and (c) $\mathrm{CTP}<35^{\circ} \mathrm{C}$.

$-1.6^{\circ} \mathrm{C}$ in CS 16 . For all the case studies except two (CS 16 and CS 20 , both in the CTP $<35^{\circ} \mathrm{C}$ range), courtyard DTR is less than outdoor DTR. The DTR evaluation supports the trend detected in the MOT, according to which a higher CTP points to the greater effectiveness of courtyard thermal tempering.

The results obtained show, as expected in the case of medium and high temperatures, that courtyard air is noticeably less susceptible to thermal changes than outdoor air. CS 18, CS 19 and CS 20 are courtyards located on the coast (Supplementary Material, Table A.1), with the mildest temperatures of all the case studies analyzed and, therefore, with the lowest DTR. The coastal cities, subsequently, have patios with a less remarkable thermal tempering performance than the rest. This factor will be decisive in the future planning of cities in a global warming environment.

\subsection{Outdoor temperature and $A R$ interaction}

According to the literature (Abdulkareem, 2016; Aldawoud, 2008; Al-Masri \& Abu-Hijleh, 2012Almhafdy et al., 2015a; Almhafdy et al., 2015b; Berkovic et al., 2012; Cantón et al., 2014; Cindel et al., 2018; Del Rio et al., 2019; Du et al., 2014; Ghaffarianhoseini et al., 2015; Guedouh \& Zemmouri, 2017Huang et al., 2016; Jihad \& Tahiri, 2016Ma et al., 2019; Manioğlu \& Oral, 2015; Martinelli \& Matzarakis, 2017Moonen et al., 2011; Muhaisen \& Gadi, 2006a; Muhaisen \& Gadi, 2006bMuhaisen, 2006; Nasrollahi et al., 2017; Qaid \& Ossen, 2015Rodríguez-Algeciras et al., 2018; Rojas et al., 2012; RojasFernández et al., 2017; Soflaei et al., 2016; Soflaei et al., 2017; Taleghani et al., 2014b; Taleghani et al., 2015; Toe \& Kubota, 2015Xu et al., 2018; Yang et al., 2012; Yaşa \& Ok, 2014; Zamani et al., 2018), $\mathrm{AR}$ is a key factor in determining courtyard thermal performance. As mentioned before, there are abundant examples of case studies in the literature (Table 1) that analyze the influence of courtyard geometry, specifically their AR, on their potential efficiency as a passive cooling system. Hence, it was decided to perform a new courtyard analysis, grouping them by AR intervals (Fig. 7). The AR intervals were clustered in four groups: $0-1,1-2,2-3$ and $>3$. The different colors in the graphs refer to different CTPs: dark gray represents CTP $>41^{\circ} \mathrm{C}$; medium gray represents CTP $35-41{ }^{\circ} \mathrm{C}$ and light gray CTP $<35{ }^{\circ} \mathrm{C}$.

The three case studies that show the best thermal performance, CS 4, CS 5 and CS 6, also have the highest AR. Other courtyards such as CS 9 and CS 11 have a slightly worse thermal performance, with a medium-high AR, while the case studies included in the lower ARs, 0-1 and 1-2 generally present the worst thermal tempering performance. In the light of these results it can be determined that, for the 20 case studies analyzed, the courtyard temperature decreases down to $3-15{ }^{\circ} \mathrm{C}$ compared to the outdoor temperature. All of this demonstrates that courtyard geometry is fundamental in terms of thermal tempering effectiveness, with correct geometry able to significantly reduce temperatures inside some building areas. In cities with more extreme temperatures, correct courtyard geometry design implies considerable energy savings and can help reduce, to some extent, the effects of climate change.

\subsection{Outdoor DTR and courtyard thermal tempering potential}

The previous results show the courtyard geometry and the outdoor thermal parameters interaction in terms of thermal tempering potential. Generally, the outdoor DTR is based on 24-h sequence, although the courtyard thermal tempering characteristic implies a more stable microclimate and greater thermal inertia than outdoor. In order to deeper understand the courtyard thermodynamic behavior; three case studies with the highest $A R>3$, the one that presents the best thermal 
$\mathrm{CTP}>41^{\circ} \mathrm{C}$

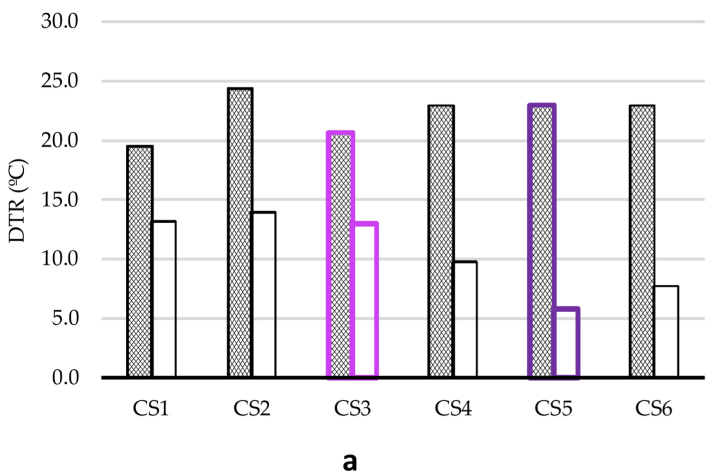

CTP $35-41^{\circ} \mathrm{C}$

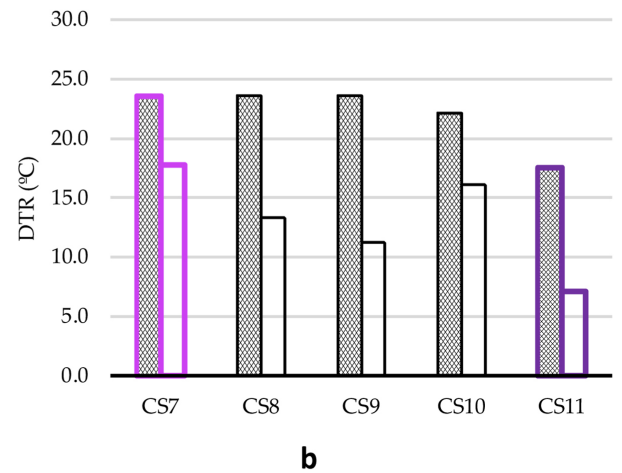

$\mathrm{CTP}<35^{\circ} \mathrm{C}$

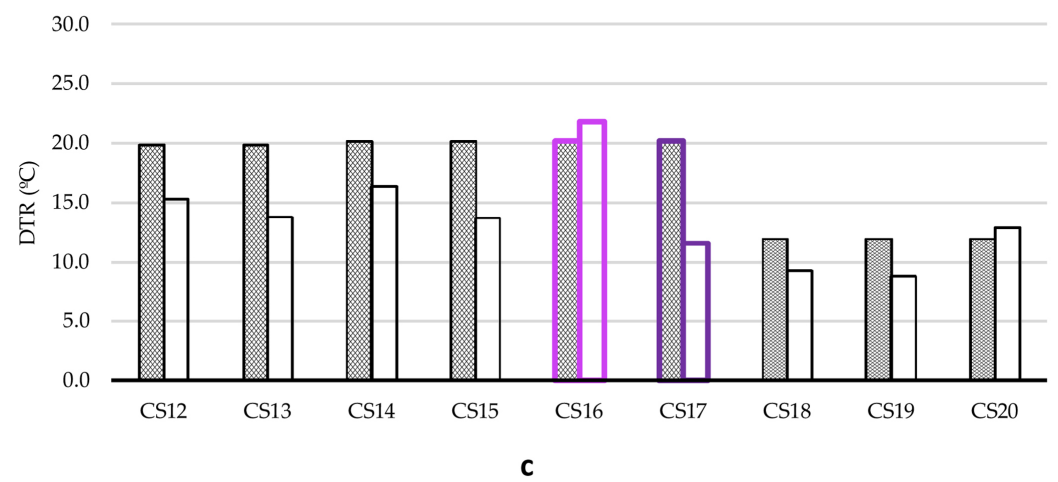
Outdoor DTR
$\square$ Courtyard DTR
口 Maximum TG
Minimum TG

Fig. 6. Outdoor-courtyard DTR comparison. (a) CTP $>41{ }^{\circ} \mathrm{C}$, (b) CTP $35-41{ }^{\circ} \mathrm{C}$ and (c) CTP $<35^{\circ} \mathrm{C}$.

AR 0-1

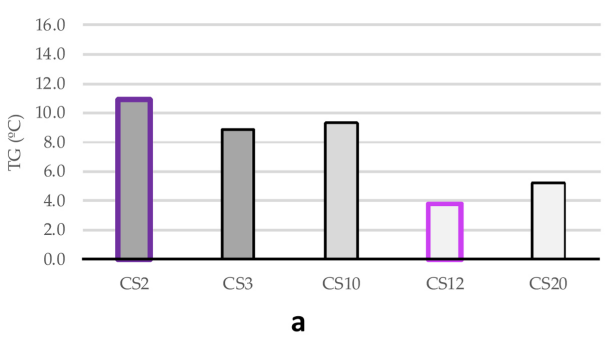

AR 2-3

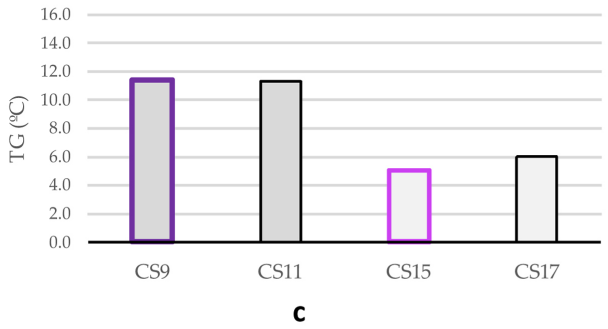

AR 1-2

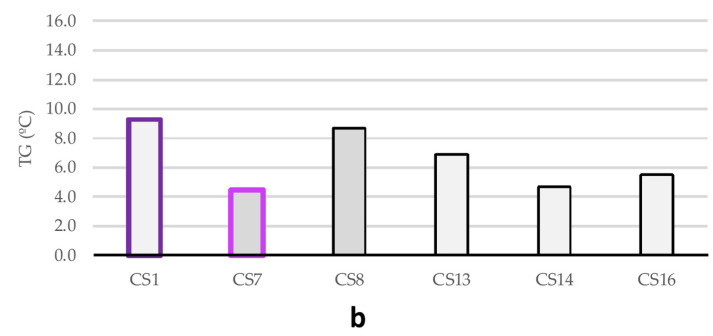

$\mathrm{AR}>3$

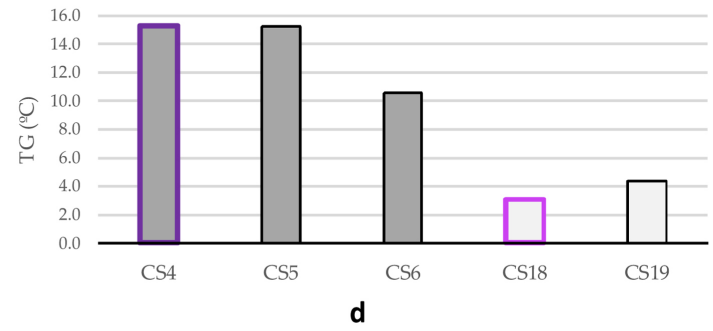

$\mathrm{CTP}>41^{\circ} \mathrm{C} \quad \square \quad \mathrm{CTP} 35-41^{\circ} \mathrm{C} \quad \square \quad \mathrm{CTP}<35^{\circ} \mathrm{C} \quad \square \quad$ Maximum TG $\quad \square \quad$ Minimum TG

Fig. 7. Mean TG based on the AR interval for all case studies. (a) AR 0-1, (b) AR 1-2, (c) AR 2-3, and (d) AR > 3.

performance, exposed to different seasonal DTRs have been compared.

The selected outdoor environments reflect three climate conditions characteristic of the southern Spain regions studied in the present work (Table 6): the DTR of a summer heat wave, with very high maximum temperatures $\left(41-45^{\circ} \mathrm{C}\right)$ and warm minimum ones $\left(20-24^{\circ} \mathrm{C}\right)(\mathrm{DTR} 1)$; the DTR of an intermediate season, indistinctly autumn or spring, with high to warm maximum temperatures $\left(28-35^{\circ} \mathrm{C}\right)$ and warm to low minimum ones $\left(12-16^{\circ} \mathrm{C}\right)$ (DTR2); and the DTR of an intermediate 
Table 6

CTPs prevalence regarding the different seasons and climatic zones studied.

\begin{tabular}{|c|c|c|c|}
\hline \multirow[t]{2}{*}{ Season } & \multicolumn{3}{|c|}{ Climate zoning } \\
\hline & $\mathrm{C} 4$ & B4 & A3 \\
\hline Summer (heat wave) & DTR1 & DTR1 & - \\
\hline Spring and/or autumn & DTR2 & DTR2 & DTR2 \\
\hline Spring/autumn close to summer & DTR3 & DTR3 & DTR2 \\
\hline
\end{tabular}

season throughout closer-to-summer weeks with fickle weather patterns involving high to warm maximum temperatures $\left(30-38^{\circ} \mathrm{C}\right)$ and warm to low minimum ones $\left(8-16^{\circ} \mathrm{C}\right)$ (DTR3).

As observed in Fig. 8, the outdoor and courtyard DTR appraisal shows different results regarding the three outdoor climate environments analyzed. Outdoor versus courtyard DTR difference rises not only in relation with the MOT considered, but proportionally to the outdoor DTR increase. This factor implies a direct consequence on the courtyard usefulness as a thermal tempering passive resource in a climate change scenario since both DTR1 and DTR3 are increasingly frequent outdoor climate environments not only in the southern European countries but in some of Central Europe.

\subsection{Discussion and correlation among significant parameters}

The results of the research carried out on 20 case studies located in different climate zones in Southern Spain show a correlation between the MOT and the potential for courtyard thermal tempering. Furthermore, this correlation is modulated by the geometrical characteristics and the AR for each courtyard. In order to define a function that links these parameters more clearly, a courtyard case study corresponding to each AR interval was selected and monitored in the three CTPs defined in the present research.

Table 7 shows the results of this comparison. As appreciated for each case study, the TG increases according to the MOT. A similar increase, although in a smaller proportion, occurs when the AR of the courtyard studied is augmented.

Fig. 9 shows the calculated and plotted TG versus the CTP for each case study representing a different AR. The fitted regression lines for TG for condition AR 0-1, AR 1-2, AR 2-3 and AR $>3$, versus CTP $<35^{\circ} \mathrm{C}$, CTP $35-41{ }^{\circ} \mathrm{C}$ and CTP $>41^{\circ} \mathrm{C}$ are as follows:

AR $0-1: y=3.25 x+0.8667\left(R^{2}=0.9599\right)$

$\mathrm{AR} 1-2: y=3.40 x+0.9928\left(R^{2}=0.9928\right)$
Table 7

MOT and AR combined influence on the courtyard thermal performance.

\begin{tabular}{|c|c|c|c|c|}
\hline & & $\mathrm{CTP}<35^{\circ} \mathrm{C}$ & CTP $35-41{ }^{\circ} \mathrm{C}$ & $\mathrm{CTP}>41{ }^{\circ} \mathrm{C}$ \\
\hline \multirow[t]{4}{*}{ CS 2 AR 0-1 } & $\operatorname{MOT}\left({ }^{\circ} \mathrm{C}\right)$ & 32.0 & 375 & 42.0 \\
\hline & $\begin{array}{l}\text { Courtyard } T_{\max } \\
\left({ }^{\circ} \mathrm{C}\right)\end{array}$ & 27.5 & 30.9 & 31.0 \\
\hline & $\mathrm{TG}\left({ }^{\circ} \mathrm{C}\right)$ & 4.5 & 6.6 & 11.0 \\
\hline & $\operatorname{MOT}\left({ }^{\circ} \mathrm{C}\right)$ & 32.0 & 37.5 & 42.0 \\
\hline \multirow[t]{2}{*}{ CS 1 AR 1-2 } & $\begin{array}{l}\text { Courtyard } \mathrm{T}_{\max } \\
\left({ }^{\circ} \mathrm{C}\right)\end{array}$ & 27.3 & 29.9 & 30.5 \\
\hline & $\mathrm{TG}\left({ }^{\circ} \mathrm{C}\right)$ & 4.7 & 7.6 & 11.5 \\
\hline \multirow[t]{3}{*}{ CS 11 AR 2-3 } & $\operatorname{MOT}\left({ }^{\circ} \mathrm{C}\right)$ & 32.0 & 37.5 & 42.0 \\
\hline & $\begin{array}{l}\text { Courtyard } T_{\max } \\
\left({ }^{\circ} \mathrm{C}\right)\end{array}$ & 26.0 & 28.8 & 30.2 \\
\hline & $\mathrm{TG}\left({ }^{\circ} \mathrm{C}\right)$ & 6.0 & 8.7 & 11.8 \\
\hline \multirow[t]{3}{*}{$\mathrm{CS} 4 \mathrm{AR}>3$} & $\operatorname{MOT}\left({ }^{\circ} \mathrm{C}\right)$ & 32.0 & 37.5 & 42.0 \\
\hline & $\begin{array}{l}\text { Courtyard } T_{\max } \\
\left({ }^{\circ} \mathrm{C}\right)\end{array}$ & 25.7 & 27.8 & 28.1 \\
\hline & TG $\left({ }^{\circ} \mathrm{C}\right)$ & 6.3 & 9.7 & 13.9 \\
\hline
\end{tabular}

AR $2-3: y=2.90 x+3.0333\left(R^{2}=0.9984\right)$

AR>3: $y=3.80 x+2.3667\left(R^{2}=0.9963\right)$

If the different linear regressions are compared, it is observed that the slopes of the lines are quite similar for all the AR intervals studied; although, the steepest slope, with a value of 3.80 , corresponds to $\mathrm{AR}>3$. The almost continuous gradation in TG values with respect to the AR increase is also observed. The results indicate this clear AR influence on courtyard thermal tempering performance but also, an even more remarkably improved courtyard cooling effectiveness as a function of the progressive outdoor thermal increase.

In order to analyze the courtyard AR interaction with the outdoor temperature values in the MOT and also throughout a whole-day cycle, it is necessary to consider the DTR. Table 8 shows the DTR gap between the outdoor and courtyard DTR for each of the AR intervals considered within three different DTR ranges.

In the same tendency as previously established for the interaction between AR and MOT, the DTR gap between the outdoor and courtyard DTR increases according to the improvement of the DTR range. In this case, AR and DTR influence on courtyard performance is quite similar and, combined, considerably increases such performance.

Fig. 10 shows the calculated and plotted DTR gap between outdoor and courtyard DTR versus the DTR range for each case study representing a different AR. The fitted regression lines for the DTR gap for condition AR 0-1, AR 1-2, AR 2-3 and AR $>3$ versus DTR $<16^{\circ} \mathrm{C}$, DTR $20-16{ }^{\circ} \mathrm{C}$ and DTR $>20^{\circ} \mathrm{C}$ are as follows:

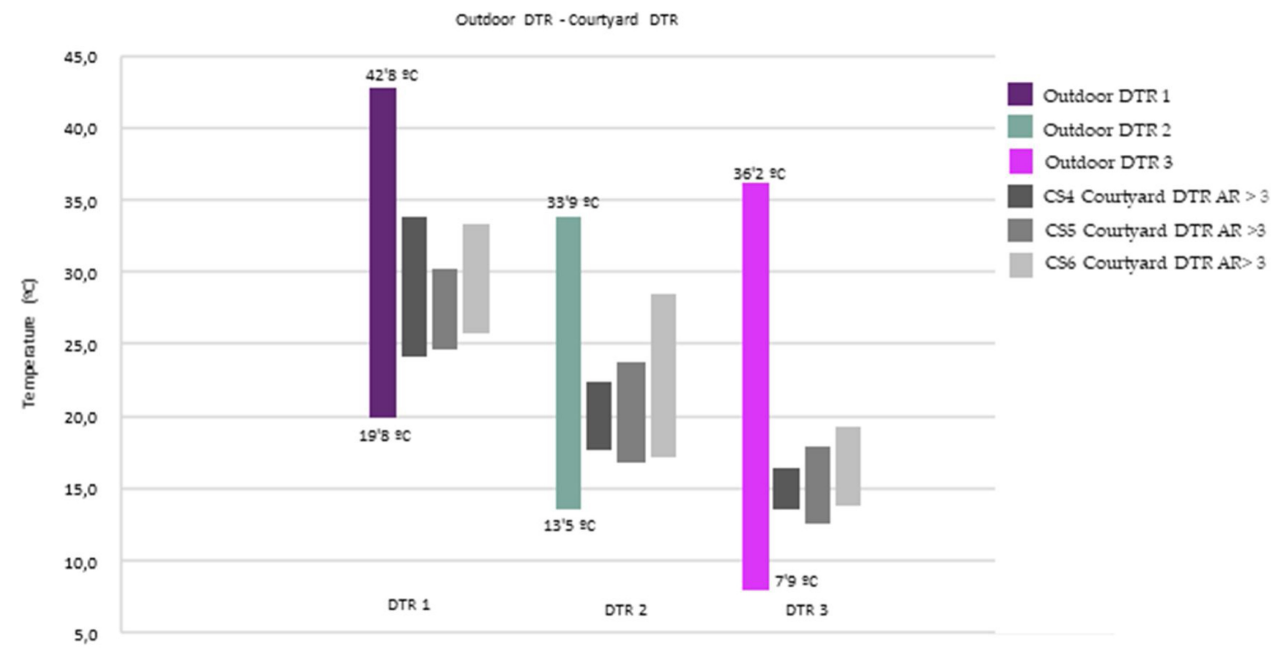

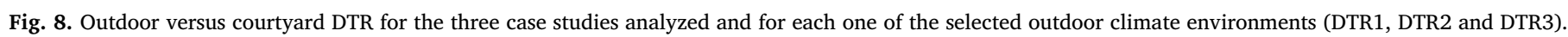




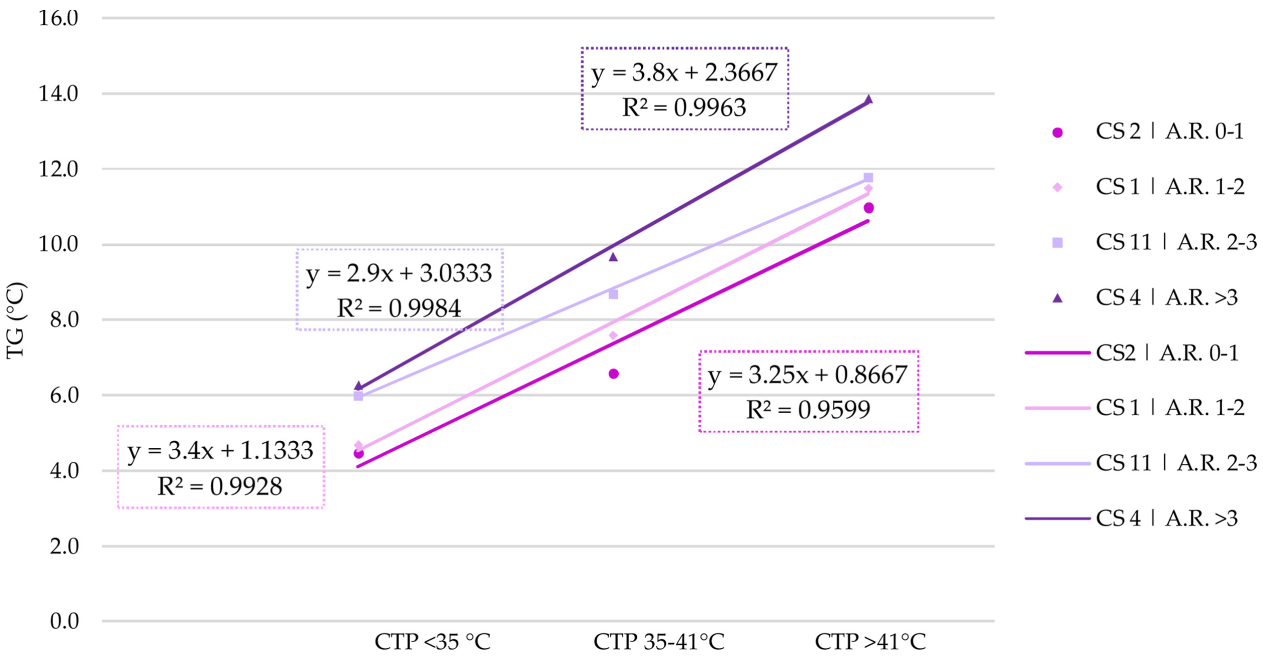

Fig. 9. Correlation between TG and CTP for each case study representing a different AR.

Table 8

DTR and AR combined influence on the courtyard thermal performance.

\begin{tabular}{|c|c|c|c|c|}
\hline & & DTR $<16^{\circ} \mathrm{C}$ & $\begin{array}{l}\text { DTR 16- } \\
20{ }^{\circ} \mathrm{C}\end{array}$ & DTR $>20^{\circ} \mathrm{C}$ \\
\hline \multirow[t]{4}{*}{ CS 2 AR 0-1 } & Outdoor DTR $\left({ }^{\circ} \mathrm{C}\right)$ & 13.2 & 14.8 & 18.9 \\
\hline & $\begin{array}{l}\text { Courtyard DTR } \\
\left({ }^{\circ} \mathrm{C}\right)\end{array}$ & 10.9 & 10.4 & 11.7 \\
\hline & DTR gap $\left({ }^{\circ} \mathrm{C}\right)$ & 2.3 & 4.4 & 7.2 \\
\hline & Outdoor DTR $\left({ }^{\circ} \mathrm{C}\right)$ & 15.2 & 17.9 & 20.3 \\
\hline \multirow[t]{2}{*}{ CS 1 AR 1-2 } & $\begin{array}{l}\text { Courtyard DTR } \\
\left({ }^{\circ} \mathrm{C}\right)\end{array}$ & 10.5 & 11.6 & 11.6 \\
\hline & DTR gap $\left({ }^{\circ} \mathrm{C}\right)$ & 4.7 & 6.3 & 8.7 \\
\hline \multirow[t]{3}{*}{ CS 11 AR 2-3 } & Outdoor DTR $\left({ }^{\circ} \mathrm{C}\right)$ & 13.2 & 14.2 & 18.8 \\
\hline & $\begin{array}{l}\text { Courtyard DTR } \\
\left({ }^{\circ} \mathrm{C}\right)\end{array}$ & 5.5 & 4.6 & 5.7 \\
\hline & DTR gap $\left({ }^{\circ} \mathrm{C}\right)$ & 7.7 & 9.6 & 13.1 \\
\hline \multirow[t]{3}{*}{$\mathrm{CS} 4 \mathrm{AR}>3$} & Outdoor DTR $\left({ }^{\circ} \mathrm{C}\right)$ & 13.8 & 17.7 & 22.6 \\
\hline & $\begin{array}{l}\text { Courtyard DTR } \\
\left({ }^{\circ} \mathrm{C}\right)\end{array}$ & 4.7 & 3.2 & 4.4 \\
\hline & DTR gap $\left({ }^{\circ} \mathrm{C}\right)$ & 9.1 & 14.5 & 18.2 \\
\hline
\end{tabular}

AR $0-1: y=2.45 x-0.2667\left(R^{2}=0.9932\right)$

AR $1-2: y=2.00 x+2.5667\left(R^{2}=0.9868\right)$

AR $2-3: y=2.70 x+4.7333\left(R^{2}=0.9716\right)$
$\mathrm{AR}>3: y=4.55 x+4.8333\left(R^{2}=0.9885\right)$

In this second correlation, when comparing the different linear regressions, it is observed that the slopes of the lines show a clear difference between the value of $A R>3$ (4.55) with respect to the other AR intervals (between 2.00 and 2.70) considered in the present study. When the DTR gap is compared, the same continuous gradation cannot be observed as when the TG is compared with respect to the different AR intervals. In this case, the results indicate a quite similar influence of the AR and DRT ranges on courtyard thermal tempering performance, with a marked increase in the case of the maximum AR.

All the data correlations set out here, lead to conclude that outdoor temperature increase results in a better courtyard performance as a passive cooling system. This ability is influenced by the control of direct radiation by means of courtyard geometry expressed in AR. Been analyzed as a thermal tempering mechanism, the courtyard is also influenced by the outdoor DTR variations. This thermal tempering mechanism becomes more evident when the outdoor DTR increases and it can be stated that, for certain geometries, the courtyard thermal buffer effect is higher than that established for a 24-h cycle. This is especially remarkable in seasons with most changeable weather and large DTRs.

\section{Conclusions}

The expected increase in the average global temperature and its

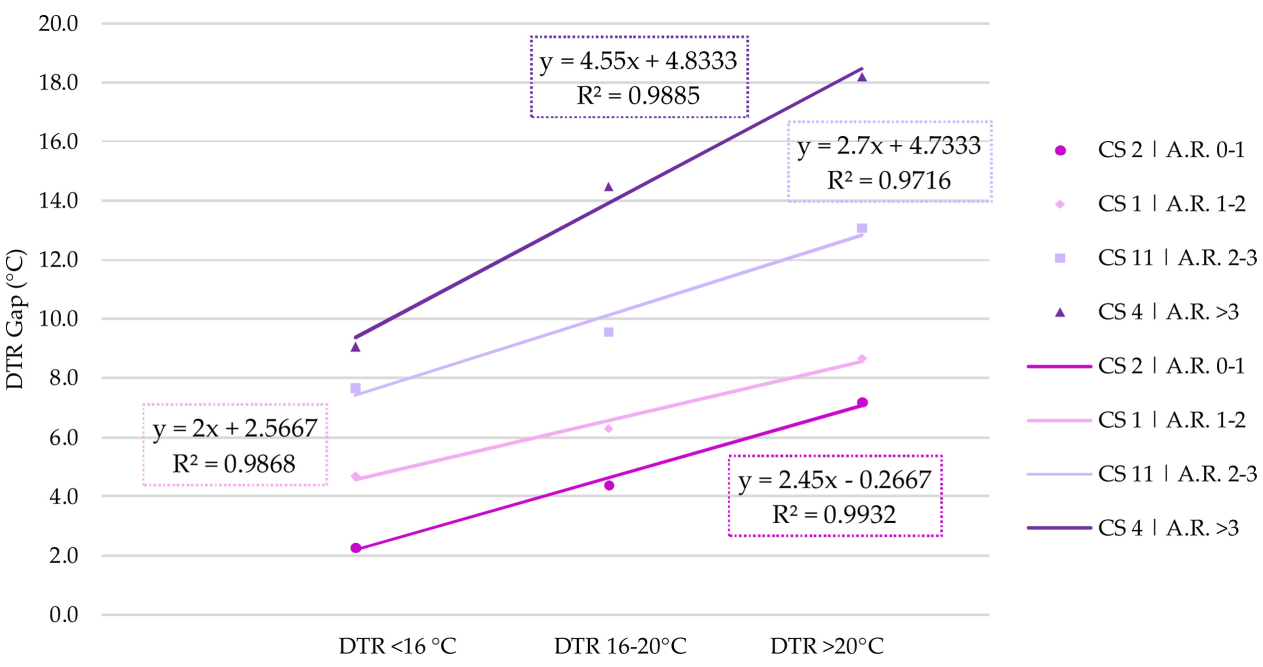

Fig. 10. Correlation between DTR gap and DTR amplitude for each case study representing a different AR. 
impact on the currently warm areas of the planet requires new architectural design strategies to be formulated that counteract the effect of overheating in buildings. The courtyard is a traditional bioclimatic resource that has been progressively abandoned for the sake of architectural globalization in cities. Therefore, considering the outdoor thermal factor as the most important variable, this paper has related different outdoor CTPs to potential courtyard cooling effectiveness by introducing courtyard geometry data as AR in the thermal tempering equation.

As revealed by the data analyzed in the extensive field monitoring campaign carried out in the present research, the courtyard tempering potential is a key element to improve the passive conditioning of buildings and cities since, for all case studies analyzed, the outdoor temperature decreases down to $3-15^{\circ} \mathrm{C}$. Implementing other strategies such as shading or vegetation in these courtyards could improve these results.

Field measurements were carried out on 20 courtyards with different ARs located in Spanish cities to find the best correlation between MOT, DTR and AR, to improve understanding of the interactions that determine courtyard microclimate behavior. In light of the results obtained, it is recommended that these three major factors be considered in combination in courtyard design with the purpose of optimizing the courtyard cooling effect.

A more detailed study shows that courtyard AR influence on its thermal tempering effectiveness is considerably increased depending on the MOT. This can be used to establish guidelines for courtyard design variants according to their location in a specific climate zone; in the present study, the courtyard AR has greater relevance in the interior cities than in cities along the coast.

The evaluation of courtyard performance in a complete daily cycle through DTR analysis supports the tendency detected for the MOT, according to which a broader CTP shows greater effectiveness in courtyard thermal tempering. It is also possible to establish a correlation between courtyard AR and the DTR gap between the outdoor and courtyard DTRs. Outdoor versus courtyard DTR gap increases not only in relation with the MOT considered but proportionally to the outdoor DTR increase.

The maximum deviation between outdoor and courtyard temperature coincides with MOT. This factor is important to establish a courtyard thermal tempering initial potential, but the daily overview through DTR analysis allows evaluating complete cycles assessing the courtyard behavior from a perspective of comfort throughout the day. The present methodology can be applied not only to the study of existing patios in different locations in order to evince these behavior patterns based on local thermal conditions, but also to determine the optimal courtyard AR design in a given location.

It can also be concluded that in the climates studied, especially in the warmest zones of the interior, deeper courtyards with $\mathrm{AR}>3$ are appropriate solutions for enhancing thermal performance. The results obtained have demonstrated that the methodological model based on MOT, DTR and AR assessment is useful for establishing a courtyard thermal performance comparison. The research has provided a background to support further research and analysis on the impact of courtyard design variants of its performance.

\section{Acknowledgments}

This work was supported by the National Government of Spain Research Projects MTM2015-64577-C2-2-R and RTI2018-093521-BC33.

\section{Appendix A. Supplementary data}

Supplementary data associated with this article can be found, in the online version, at https://doi.org/10.1016/j.scs.2019.101740.

\section{References}

Abdulkareem, H. A. (2016). Thermal comfort through the microclimates of the courtyard. A critical review of the middle-eastern courtyard house as a climatic response. Procedia - Social and Behavioral Sciences, 216(October 2015), 662-674. https://doi. org/10.1016/j.sbspro.2015.12.054.

Resúmenes climatológicos - España - Anuales - Agencia Estatal de Meteorología - AEMET. Gobierno de España. http://www.aemet.es/es/serviciosclimaticos/vigilancia_clima/ resumenes? $\mathrm{w}=0$ \&datos $=2$. Accessed 15.01.2019.

Aldawoud, A. (2008). Thermal performance of courtyard buildings. Energy and Buildings, 40(5), 906-910. https://doi.org/10.1016/j.enbuild.2007.07.007.

Al-Masri, N., \& Abu-Hijleh, B. (2012). Courtyard housing in midrise buildings: An environmental assessment in hot-arid climate. Renewable Sustainable Energy Reviews, 16(4), 1892-1898. https://doi.org/10.1016/j.rser.2012.01.008.

Almhafdy, A., Ibrahim, N., Ahmad, S. S., \& Yahya, J. (2013). Analysis of the courtyard functions and its design variants in the Malaysian hospitals. Procedia - Social and Behavioral Sciences, 105, 171-182. https://doi.org/10.1016/j.sbspro.2013.11.018.

Almhafdy, A., Norhati, I., Sh Ahmad, S., \& Yahya, J. (2015a). Courtyard design variants and microclimate performance. New Phytology, 206(1), 397-410. https://doi.org/10. 1111/nph.13184.

Almhafdy, A., Ibrahim, N., Ahmad, S. S., \& Yahya, J. (2015b). Thermal performance analysis of courtyards in a hot humid climate using computational fluid dynamics CFD method. Procedia - Social and Behavioral Sciences, 170, 474-483. https://doi.org/ 10.1016/j.sbspro.2015.01.012.

Alvarez, S., Sanchez, F., \& Molina, J. L. (1998). Flow pattern at courtyards. In E. M. S. Yannas (Ed.). Enviromentally Friendly Cities. Lisbon (pp. 503-506).

Berkovic, S., Yezioro, A., \& Bitan, A. (2012). Study of thermal comfort in courtyards in a hot arid climate. Solar Energy, 86(5), 1173-1186. https://doi.org/10.1016/j.solener. 2012.01.010.

Bitan, A. (1988). The methodology of applied climatology in planning and building Energy and Buildings, 11(1-3), 1-10. https://doi.org/10.1016/0378-7788(88) 90018-7.

Cantón, M. A., Ganem, C., Barea, G., \& Llano, J. F. (2014). Courtyards as a passive strategy in semi dry areas. Assessment of summer energy and thermal conditions in a refurbished school building. Renewable Energy, 69, 437-446. https://doi.org/10. 1016/j.renene.2014.03.065.

Cindel, S., Yung, Y., Norhayati, M., \& Norafida, A. G. (2018). An overview of influencing factors of thermal performance for open spaces in the tropics. Journal of Design and Built Environment, 18(December), 1-14.

Documento Básico E. CTE. Código técnico de la Edificación. Documento Básico HE Ahorro de Energía. https://www.codigotecnico.org/images/stories/pdf/ahorroEnergia/ DBHE.pdf. Accessed 15.01.2019.

Del Rio, M. A., Asawa, T., Hirayama, Y., Sato, R., \& Ohta, I. (2019). Evaluation of passive cooling methods to improve microclimate for natural ventilation of a house during summer. Building and Environment, 149, 275-287. https://doi.org/10.1016/j. buildenv.2018.12.027.

Du, X., Bokel, R., \& van den Dobbelsteen, A. (2014). Building microclimate and summer thermal comfort in free-running buildings with diverse spaces: A Chinese vernacular house case. Building and Environment, 82, 215-227. https://doi.org/10.1016/j. buildenv.2014.08.022.

Easterling, D. R., Horton, B., Jones, P. D., et al. (1997). Maximum and minimum temperature trends for the globe. Science (80-), 277(5324), 364-367. https://doi.org/10. 1126 /science.277.5324.364

Fong, C. S., Aghamohammadi, N., Ramakreshnan, L., Sulaiman, N. M., \& Mohammadi, P. (2019). Holistic recommendations for future outdoor thermal comfort assessment in tropical Southeast Asia: A critical appraisal. Sustainable Cities and Society, 46(April), https://doi.org/10.1016/j.scs.2019.101428.

Ghaffarianhoseini, A., Berardi, U., \& Ghaffarianhoseini, A. (2015). Thermal performance characteristics of unshaded courtyards in hot and humid climates. Building and Environment, 87, 154-168. https://doi.org/10.1016/j.buildenv.2015.02.001.

Guedouh, M. S., \& Zemmouri, N. (2017). Courtyard building's morphology impact on thermal and luminous environments in hot and arid region. Energy Procedia, 119, 153-162. https://doi.org/10.1016/j.egypro.2017.07.063.

Guimarães Merçon, M. (2008). Confort Térmico y Tipología Arquitectónica en Clima CálidoHúmedo Análisis térmico de la cubierta ventilada Confort Térmico y Tipología Arquitectónica en Clima Cálido-Húmedo Análisis térmico de la cubierta ventilada. https:// wwwaie.webs.upc.edu/maema/wp-content/uploads/2016/06/Guimaraes-MerconMariana-Confort-termico-y-tipologia-en-clima-calido-humedo-TC.pdf.

Huang, L., Hamza, N., Lan, B., \& Zahi, D. (2016). Climate-responsive design of traditional dwellings in the cold-arid regions of Tibet and a field investigation of indoor environments in winter. Energy and Building, 128, 697-712. https://doi.org/10.1016/j. enbuild.2016.07.006.

Junta de Andalucía Evolución de las principales variables climáticas actualizadas al $4^{\circ}$ Informe del IPCC. http://www.juntadeandalucia.es/medioambiente/site/portalweb/ menuitem. Accessed 05.02.2019.

Jihad, A. S., \& Tahiri, M. (2016). Modeling the urban geometry influence on outdoor thermal comfort in the case of Moroccan microclimate. Urban Climate, 16(June), 25-42. https://doi.org/10.1016/j.uclim.2016.02.002.

Junta de Andalucía. Regiones climáticas de Andalucía. http://www.juntadeandalucia.es/ medioambiente/site/portalweb/menuitem. Accessed 05.02.2019.

Kottek, M., Grieser, J., Beck, C., Rudolf, B., \& Rubel, F. (2006). World map of the Köppen-Geiger climate classification updated. Meteorologische Zeitschrift, 15(3), 259-263. https://doi.org/10.1127/0941-2948/2006/0130.

Lee, W., Kim, Y., Honda, Y., \& Kim, H. (2018a). Association between diurnal temperature range and mortality modified by temperature in Japan, 1972-2015: Investigation of 
spatial and temporal patterns for 12 cause-specific deaths. Environment International, 119, 379-387. https://doi.org/10.1016/j.envint.2018.06.020.

Lee, W., Bell, M. L., Gasparrini, A., et al. (2018b). Mortality burden of diurnal temperature range and its temporal changes: A multi-country study. Environment International, 110, 123-130. https://doi.org/10.1016/j.envint.2017.10.018.

López-Cabeza, V. P., Galán-Marín, C., Rivera-Gómez, C., \& Roa-Fernández, J. (2018) Courtyard microclimate ENVI-met outputs deviation from the experimental data. Building and Environment, 144, 129-141. https://doi.org/10.1016/j.buildenv.2018. 08.013.

Ma, X., Fukuda, H., Zhou, D., Gao, W., \& Wang, M. (2019). The study on outdoor pedestrian thermal comfort in blocks: A case study of the Dao He Old Block in hotsummer and cold-winter area of southern China. Solar Energy, 179, 210-225. https:// doi.org/10.1016/j.solener.2018.12.001.

Manioğlu, G., \& Oral, G. K. (2015). Effect of courtyard shape factor on heating and cooling energy loads in hot-dry climatic zone. Energy Procedia, 78, 2100-2105. https://doi.org/10.1016/j.egypro.2015.11.250.

Martinelli, L., \& Matzarakis, A. (2017). Influence of height/width proportions on the thermal comfort of courtyard typology for Italian climate zones. Sustainable Cities and Society, 29, 97-106. https://doi.org/10.1016/j.scs.2016.12.004.

Mediterranean Experts on Climate and Environmental Change. http://www.medecc.org/. Accessed 05.02.2019.

Moonen, P., Dorer, V., \& Carmeliet, J. (2011). Evaluation of the ventilation potential of courtyards and urban street canyons using RANS and LES. Journal of Wind Engineering and Industrial Aerodynamics, 99(4), 414-423. https://doi.org/10.1016/j.jweia.2010. 12.012.

Muhaisen, A. S. (2006). Shading simulation of the courtyard form in different climatic regions. Building and Environment, 41(12), 1731-1741. https://doi.org/10.1016/j. buildenv.2005.07.016.

Muhaisen, A. S., \& Gadi, B. M. (2006a). Shading performance of polygonal courtyard forms. Building and Environment, 41(8), 1050-1059. https://doi.org/10.1016/j. buildenv.2005.04.027.

Muhaisen, A. S., \& Gadi, M. B. (2006b). Effect of courtyard proportions on solar heat gain and energy requirement in the temperate climate of Rome. Building and Environment, 41(3), 245-253. https://doi.org/10.1016/j.buildenv.2005.01.031.

Nakano, A. (2015). Urban weather generator user interface development: Towards a usable tool for integrating urban heat island effect within urban design process, 3. (2) http:// www.meteo.fr/icuc9/LongAbstracts/udc5-1-1171051_a.pdf.

Nasrollahi, N., Hatami, M., Khastar, S. R., \& Taleghani, M. (2017). Numerical evaluation of thermal comfort in traditional courtyards to develop new microclimate design in a hot and dry climate. Sustainable Cities and Society, 35(November), 449-467. https:// doi.org/10.1016/j.scs.2017.08.017.

Pyrgou, A., Castaldo, V. L., Pisello, A. L., Cotana, F., \& Santamouris, M. (2017). On the effect of summer heatwaves and urban overheating on building thermal-energy performance in central Italy. Sustain Cities and Society, 28, 187-200. https://doi.org/ 10.1016/j.scs.2016.09.012.

Qaid, A., \& Ossen, D. R. (2015). Effect of asymmetrical street aspect ratios on microclimates in hot, humid regions. International Journal of Biometeorology, 59(6), 657-677. https://doi.org/10.1007/s00484-014-0878-5.

Rodríguez-Algeciras, J., Tablada, A., Chaos-Yeras, M., De la Paz, G., \& Matzarakis, A. (2018). Influence of aspect ratio and orientation on large courtyard thermal conditions in the historical centre of Camagüey-Cuba. Renewable Energy, 125, 840-856. https://doi.org/10.1016/j.renene.2018.01.082.

Rojas, J. M., Galán-Marín, C., \& Fernández-Nieto, E. D. (2012). Parametric study of thermodynamics in the mediterranean courtyard as a tool for the design of eco-efficient buildings. Energies, 5(7), 2381-2403. https://doi.org/10.3390/en5072381.

Rojas-Fernández, J., Galán-Marín, C., Roa-Fernández, J., \& Rivera-Gómez, C. (2017). Correlations between GIS-based urban building densification analysis and climate guidelines for mediterranean courtyards. Sustainability, 9(12), 2255. https://doi.org/ 10.3390/su9122255.

Rubio-Bellido, C., Pulido-Arcas, J. A., \& Ureta-Gragera, M. (2015). Aplicabilidad de estrategias genéricas de diseño pasivo en edificaciones bajo la influencia del cambio climático en Concepción y Santiago, Chile. Hábitat Sustentable, 5(2), 33-41.

Salata, F., Golasi, I., Vollaro, A. D. L., \& Vollaro, R. D. L. (2015). How high albedo and traditional buildings' materials and vegetation affect the quality of urban microclimate. A case study. Energy and Buildings, 99, 32-49. https://doi.org/10. 1016/j.enbuild.2015.04.010.

Shahidan, M. F., Jones, P. J., Gwilliam, J., \& Salleh, E. (2012). An evaluation of outdoor and building environment cooling achieved through combination modification of trees with ground materials. Building and Environment, 58(December), 245-257. https://doi.org/10.1016/j.buildenv.2012.07.012.

Shashua-Bar, L., Pearlmutter, D., \& Erell, E. (2009). The cooling efficiency of urban landscape strategies in a hot dry climate. Landscape and Urban Planning, 92(3-4), 179-186. https://doi.org/10.1016/j.landurbplan.2009.04.005.

Soflaei, F., Shokouhian, M., \& Mofidi Shemirani, S. M. (2016). Traditional Iranian courtyards as microclimate modifiers by considering orientation, dimensions, and proportions. Frontiers of Architectural Research, 5(2), 225-238. https://doi.org/10. 1016/j.foar.2016.02.002.

Soflaei, F., Shokouhian, M., Abraveshdar, H., \& Alipour, A. (2017). The impact of courtyard design variants on shading performance in hot- arid climates of Iran. Energy and Buildings, 143, 71-83. https://doi.org/10.1016/j.enbuild.2017.03.027.

Stocker, T. F., Qin, D., Plattner, G. K., Alexander, L. V., Allen, S. K., Bindoff, N. L., et al. (2013). CLIMATE CHANGE 2013 The physical science basis summary for policymakers, technical summary and frequently asked questions. http://www.cdc.gov/mmwr/ preview/mmwrhtml/00000168.htm.

Taleghani, M. (2018). Outdoor thermal comfort by different heat mitigation strategies - A review. Renewable Sustainable Energy Reviews, 81(October 2016), 2011-2018. https:// doi.org/10.1016/j.rser.2017.06.010.

Taleghani, M., Tenpierik, M., \& van den Dobbelsteen, A. (2014a). Energy performance and thermal comfort of courtyard/atrium dwellings in the Netherlands in the light of climate change. Renewable Energy, 63, 486-497. https://doi.org/10.1016/j.renene. 2013.09.028.

Taleghani, M., Tenpierik, M., \& van den Dobbelsteen, A. (2014b). Indoor thermal comfort in urban courtyard block dwellings in the Netherlands. Building and Environment, 82, 566-579. https://doi.org/10.1016/j.buildenv.2014.09.028.

Taleghani, M., Tenpierik, M., van den Dobbelsteen, A., \& Sailor, D. J. (2014ca). Heat mitigation strategies in winter and summer: Field measurements in temperate climates. Building and Environment, 81, 309-319. https://doi.org/10.1016/j.buildenv. 2014.07.010.

Taleghani, M., Tenpierik, M., van den Dobbelsteen, A., \& Sailor, D. J. (2014cb). Heat in courtyards: A validated and calibrated parametric study of heat mitigation strategies for urban courtyards in the Netherlands. Solar Energy, 103, 108-124. https://doi.org/ 10.1016/j.solener.2014.01.033.

Taleghani, M., Kleerekoper, L., Tenpierik, M., \& van den Dobbelsteen, A. (2015). Outdoor thermal comfort within five different urban forms in the Netherlands. Building and Environment, 83, 65-78. https://doi.org/10.1016/j.buildenv.2014.03.014.

Toe, D. H. C., \& Kubota, T. (2015). Comparative assessment of vernacular passive cooling techniques for improving indoor thermal comfort of modern terraced houses in hot-humid climate of Malaysia. Solar Energy, 114, 229-258. https://doi.org/10.1016/j. solener.2015.01.035.

United Nations (2019). Climate change. http://www.un.org/en/sections/issues-depth/ climate-change/index.html. Accessed 05.02.2019.

United Nations (2015). The Paris agreements. https://unfccc.int/resource/docs/2015/ cop21/eng/10a01.pdf.

Vinnarasi, R., Dhanya, C. T., Chakravorty, A., \& AghaKouchak, A. (2017). Unravelling diurnal asymmetry of surface temperature in different climate zones. Scientific Reports, 7(1), 7350. https://doi.org/10.1038/s41598-017-07627-5.

Xu, X., Luo, F., Wang, W., Hong, T., \& Fu, X. (2018). Performance-based evaluation of courtyard design in china's cold-winter hot-summer climate regions. Sustainability, 10(11), 3950. https://doi.org/10.3390/su10113950.

Yang, X., Li, Y., \& Yang, L. (2012). Predicting and understanding temporal 3D exterior surface temperature distribution in an ideal courtyard. Building and Environment, 57, 38-48. https://doi.org/10.1109/NOORIC.2013.76.

Yaşa, E., \& Ok, V. (2014). Evaluation of the effects of courtyard building shapes on solar heat gains and energy efficiency according to different climatic regions. Energy and Buildings, 73, 192-199. https://doi.org/10.1016/j.enbuild.2013.12.042.

Zamani, Z., Heidari, S., \& Hanachi, P. (2018). Reviewing the thermal and microclimatic function of courtyards. Renewable Sustainable Energy Reviews, 93(April), 580-595. https://doi.org/10.1016/j.rser.2018.05.055. 